\title{
Identification and epidemiological evaluation of gastric cancer risk factors: based on a field synopsis and meta-analysis in Chinese population
}

\author{
Fujiao Duan ${ }^{1,2,4}$, Chunhua Song ${ }^{1,2}$, Jiachen Shi ${ }^{3}$, Peng Wang ${ }^{1,2}$, Hua Ye ${ }^{1,2}$, Liping Dai ${ }^{1,2}$, \\ Jianying Zhang ${ }^{1,2}$, Kaijuan Wang ${ }^{1,2}$ \\ ${ }^{1}$ College of Public Health, Zhengzhou University, Zhengzhou, Henan Province, China \\ ${ }^{2}$ Key Laboratory of Tumor Epidemiology of Henan Province, Zhengzhou, Henan Province, China \\ ${ }^{3}$ Department of Internal Medicine, The First Affiliated Hospital of Zhengzhou University, Zhengzhou, Henan \\ Province, China \\ ${ }^{4}$ Medical Research Office, Affiliated Cancer Hospital of Zhengzhou University, Zhengzhou, Henan Province, China
}

Correspondence to: Kaijuan Wang; email: wkj@zzuedu.cn

Keywords: gastric cancer, risk factors, genetic variants, susceptibility, field synopsis

Received: January 10, $2021 \quad$ Accepted: August 11, $2021 \quad$ Published: August 6, 2021

Copyright: (C) 2021 Duan et al. This is an open access article distributed under the terms of the Creative Commons Attribution License (CC BY 3.0), which permits unrestricted use, distribution, and reproduction in any medium, provided the original author and source are credited.

\section{ABSTRACT}

To summarize and assess the credibility and strength of non-genetic factors and genetic variation on gastric cancer risk, we performed a field synopsis and meta-analysis to identify the risk of gastric cancer in Chinese population. Cumulative evidence was graded according to the Venice criteria, and attributable risk percentage (ARP) and population attributable risk percentage (PARP) were used to evaluate the epidemiological effect. A total of 956 studies included non-genetic (404 studies) and genetic factors (552 studies) were quantified, and data on 1161 single nucleotide polymorphisms (SNPs) were available. We identified 14 non-genetic factors were significantly associated with gastric cancer risk. For the analysis of time trends, $H$. pylori infection rate in gastric cancer and population showed a downward trend. Meanwhile 22 variants were identified significantly associated with gastric cancer: 3 (PLCE1 rs2274223, PSCA rs2976392, MUC1 rs4072037) were high and 19 SNPs were intermediate level of summary evidence, respectively. For non-genetic factors, the top three for ARP were $54.75 \%$ (pickled food), $65.87 \%$ (stomach disease), and 49.75\% (smoked and frying). For PARP were $34.22 \%$ (pickled food), 34.24\% (edible hot food) and $23.66 \%(H$. pylori infection). On the basis of ARP and PARP associated with SNPs of gastric cancer, the top three for ARP were 53.91\% (NAT2, rs1799929),53.05\% (NAT2 phenotype), and 42.85\% (IL-10, rs1800896). For PARP (Chinese Han in Beijing) were 36.96\% (VDR, rs731236), 25.58\% (TGFBR2, rs3773651) and 20.56\% (MUC1, rs4072037). Our study identified non-genetic risk factors and high-quality biomarkers of gastric cancer susceptibility and their contribution to gastric cancer.

\section{INTRODUCTION}

Cancer is a major public health problem in the world [1]. Gastric cancer is a highly lethal malignancy worldwide, being the fourth most common cancer and the second leading cause of cancer-related mortality [2]. Among the total cancer mortality rates, male and female gastric cancer mortality rates accounted for $30 \%$ and $20 \%$, respectively [3]. It is concerning that Eastern Asia had the highest estimated morbidity and mortality rates worldwide [4]. In China, gastric cancer is the second most commonly diagnosed cancer among men, second only to lung cancer [5]. Although surgical techniques, radiotherapy and chemotherapy regimens have helped 
reduce the incidence and mortality rates of gastric cancer [6] the overall 5-year survival rate is still only approximately $25 \%[7,8]$.

The pathogenesis of gastric cancer represents a typical example of gene-environment interaction [9]. Among environmental factors, unhealthy eating habits or behavior and Helicobacter pylori (H. pylori) infection are the most common causes of gastric cancer. Because of the functional variation of genes, genetic factors play a crucial role in the development of gastric cancer, leading to cancer outcomes [10].

In the past two decades, several strategies have been used to determine the genetic determinants of gastric cancer, including $H$. pylori eradication, precancerous lesions, genome wide association study (GWAS) and identification of candidate genes. Moreover, based on GWAS results, about 11 sites in the human genome have been reported to link with the development of gastric cancer in Chinese population [11].

In actuality, before the emergence and widespread use of genome-wide scanning, hundreds of case-control studies have detected candidate polymorphisms (mainly based on rational selection of Biology) in gastric cancer. Although some of these associations showed hope, almost all of them failed to replicate [12]. In order to explore the role of genetic variation in the occurrence of gastric cancer, a large number of studies have been carried out, and genetic variation are considered as potential risk factors of gastric cancer. Interestingly, different DNA variants appear to be associated with the risk of specific sites of gastric cancer. However, the results of these studies are not always consistent. So far, no systematic review covering all polymorphisms and non-genetic factors has been published in Chinese population,

The aim of this study is to fill this gap in medical research literature on Chinese population from international and Chinese public databases by presenting the first systematic review of the available evidence in field of non-genetic $(H$. pylori infection, family history, behavioral factors (ie, smoking, drinking and diet, et al.), mental depression and other factors (ie, obesity, hypertension and diabetes)) and genetic factors (single nucleotide polymorphisms, SNPs) and the risk of gastric cancer, including the evaluation of their epidemiological significance.

\section{RESULTS}

\section{Study identification}

A flow diagram of the literature search strategy was summarized in Figure 1. Based on the search strategy, a total of 6,637 records were retrieved. Of these, 3,900 articles were excluded as duplicates, 998 articles were excluded as irrelevant (not related to risk factors or genetic variants). After screening the titles and abstracts, the remaining 852 eligible articles were assessed for full-text review. Due to most independent studies included non-genetic and genetic factors associated with gastric cancer, and therefore 639 articles $(n=399$ articles, 404 studies for non-genetic factors; $\mathrm{n}=547$ articles, 552 studies for genetic factors) eligible articles were included in qualitative synthesis (Supplementary References). If an article contains two populations, we consider it as two independent studies. The SNP was eliminated if the number of studies involving it was less than 3 . As a result, a total of 70 SNPs involving 48 genes were available. We calculated the Hardy-Weinberg equilibrium (HWE) based on the control genotyping data provided by the eligible study, and 114 studies (14 SNPs involved 10 genes) were excluded due to the non-HWE. Therefore, 56 SNPs involved 38 genes were quantitative synthesis.

\section{Baseline characteristics of eligible studies}

Non-genetic factors data set from 404 studies containing 161,960 cases and 218,270 controls and genetic factors data set from 552 studies providing genotype data on 844,632 cases and 1,101,997 controls of Chinese population

Based on the design, most of the data sets of nongenetic factors $(263 / 399,65.91 \%)$ and genetic factors $(65.04 \%, 359 / 552)$ are derived from population-based case-control articles. 378 articles $(69.10 \%, 378 / 547)$ was randomly repeated a portion of samples as quality control while genotyping to evaluate reproducibility and accuracy.

A total of 16 non-genetic factors were extracted, namely $H$. pylori infection, smoking, drinking, family history, stomach disease, high salt diet, pickled food, fast eating, irregular meals, edible hot food, smoked and frying, spicy diet, mental depression, BMI, Hypertension, Diabetes.

For genetic factors, partial inclusion studies specified the histological subtypes (intestinal, diffuse or mix) $(10.07 \%, 59 / 552)$ of gastric cancer, the site (cardia and non-cardia) $(15.04 \%, 83 / 552)$ of the primary gastric cancer and $H$. pylori infection status (positive vs negative) $(13.22 \%, 73 / 552)$.

PubMed was used to identify GWAS associated with gastric cancer, resulting in a total of three GWASs (11 SNPs) [13-15], the11 SNPs were all located in 5 genes. Overall, data on 1161 polymorphisms involving 460 
distinct genes were available. Most SNPs were located on chromosomes 1 and 8 . The number of articles from Jiangsu Province was the highest (218), followed by Shandong (38) and Henan (37) Province. The distribution of $H$. pylori infection in the general population and gastric cancer based on China's regional division was shown in Figure 2A, 2B.

\section{Quantitative synthesis findings}

Demographic and environmental risk factors for gastric cancer were summarized in Table 1. H. pylori infection, smoking, drinking, family history, stomach disease, high salt diet, pickled food, fast eating, irregular meals, edible hot food, smoked and frying, spicy diet and mental depression were significantly associated with gastric cancer risk. Of note, the results showed that the risk of gastric cancer in diabetic patients was lower than that in the general population $(O R=0.76,95 \% \mathrm{CI}$ : 0.68-0.84), while hypertension $(O R=0.95,95 \% C I$ : 0.88-1.01) and obesity (BMI, OR $=0.79,95 \%$ CI: 0.531.21) were not associated with gastric cancer. According to the type of gastric cancer, the results showed that the risk factors for cardia and non-cardia

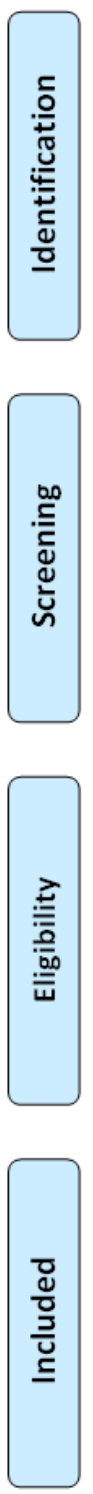

Records identified through database searching ( $n=6637)$

Web of Science $(n=1739)$, PubMed $(n=1127)$, EMBASE $(n=667)$

Cochrane Library (673), CBM ( $n=597)$, VIP (501)

Wanfang $(n=768)$, CNKI $(n=565)$

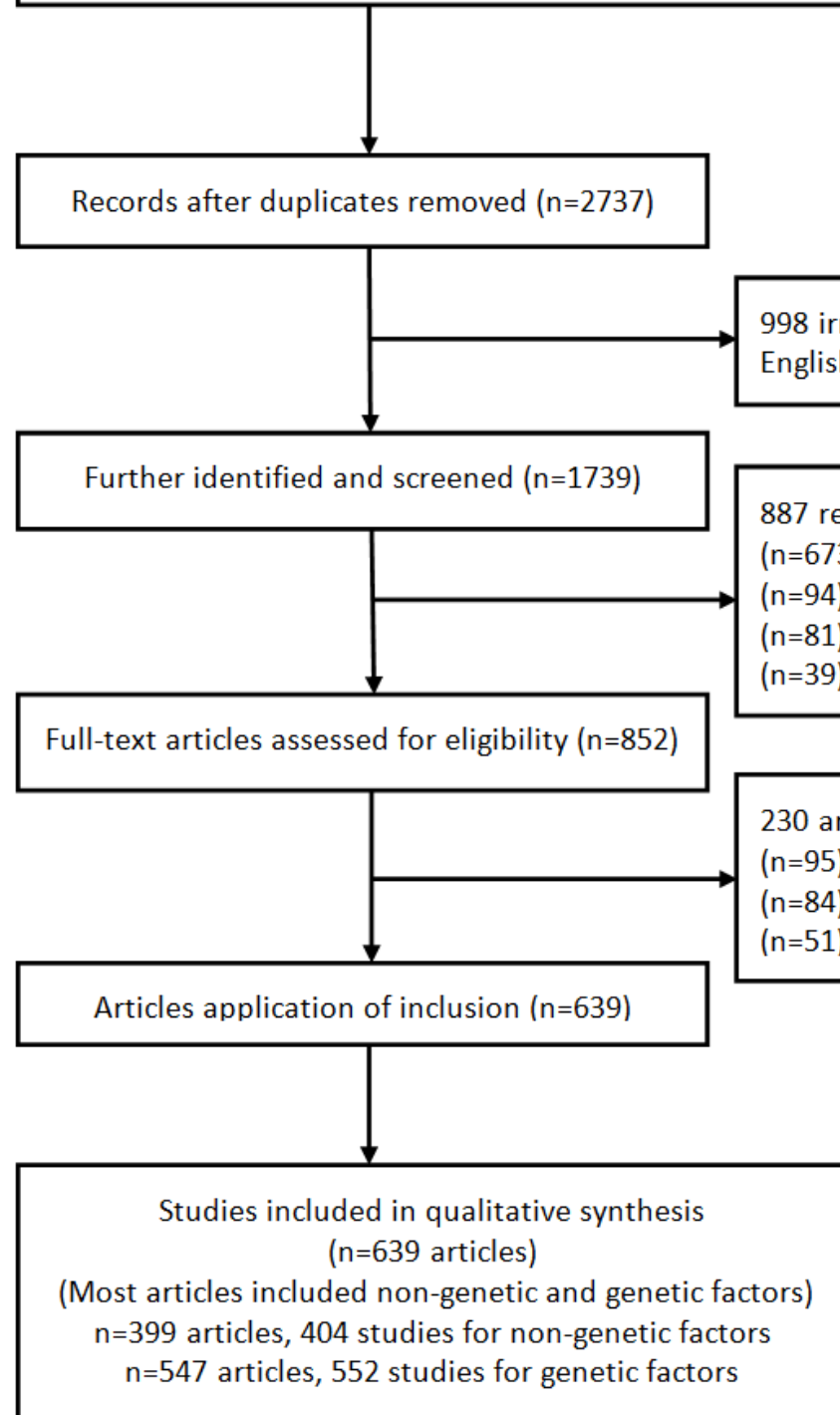

Figure 1. Flow chart of literature search and study selection. 
gastric cancers were different (Table 1). Meanwhile, linear regression analysis showed that from 2000 to 2020, H. pylori infection rate showed a slowly downward trend in gastric cancer and population, and it was relatively obvious in the population (Figure 3 ).

Based on the number of studies, the number of studies ranged from 3 to 23, the top five genetic variations were the following: GSTMI (1p13.3), GSTT1 (22q11.23), MTHFR (rs 1801133), XRCCl (rs1799782) and XRCCI (rs25487).

Among the significant associations identified by this synopsis, the level of summary evidence 3(13.64\%) (PLCE1 rs2274223, PSCA rs2976392, MUClrs4072037) were high and 19 (83.36\%) (MTHFR rs1801133, COX-2 rs20417, XRCC1 rs1799782 and rs25487, XRCC3 rs861539, NAT2 rs1799930 and rs1799929, PLCE1 rs3765524, GSTM1, GSTT1IL-17A rs2275913 and rs8193036, PSCA rs2294008, PRKAA1 rs13361707, ERCC5 rs751402, TGFBR rs3773651, IL-10 rs1800896 and $V D R$ rs731236) were intermediate level of summary evidence, respectively. The default value of FPRP critical value was 0.5 , and the prior probability was set as $0.1,0.01$ and 0.001 respectively. Among the high-quality correlations, FPRP was the best for $22 / 22,19 / 22$ and $6 / 22$ at $0.1,0.01$ and 0.001 levels, respectively. The details of significant associations characterized by a high or intermediate level of pooled evidence were summarized in Table 2 . According to the main functions of genes, the distribution of genetic variants significantly related to the risk of gastric cancer were shown in Figure 4A4D. As we add more susceptible genes into the model, the risk distribution gradually expands, and the population can better distinguish between high-risk and low-risk categories.

Association between the genetic variants and risk of gastric cancer in different comparisons were shown in Table 3.

\section{Sensitivity analysis and publication bias}

We conducted the sensitivity analysis by omitting each study in turn on the pooled ORs, and removing any of the included studies, there was no significant impact on the pooled outcomes, which indicated the pooled OR was stable (Data not shown). The publication bias of the included studies was evaluated through Begger's and Egger's tests. The results indicated no evidence of publication bias.

Begger's $(t=0.69, P=0.466$ for non-genetic factors; $t=1.44$, $P=0.163$ for genetic factors) and Egger's test $(t=0.93$, $P=0.367$, 95CI: $-0.359,1.203$ for non-genetic factors; $t=0.69, P=0.131$, 95CI: $-0.122,1.1317$ for genetic factors) were used to evaluate the publication bias.

\section{Epidemiological evaluation of risk factors}

The combined distribution of the correlation strength $(O R)$ of the 13 risk factors $(O R>1.20)$ and the accumulation frequency of the risk factors was shown in Figure 5A, a total of 8,192 combinations were generated by random combination. Q-Q plot showed that the two data sets were from a population with common distribution, which conforms to normal distribution (Figure 5B).
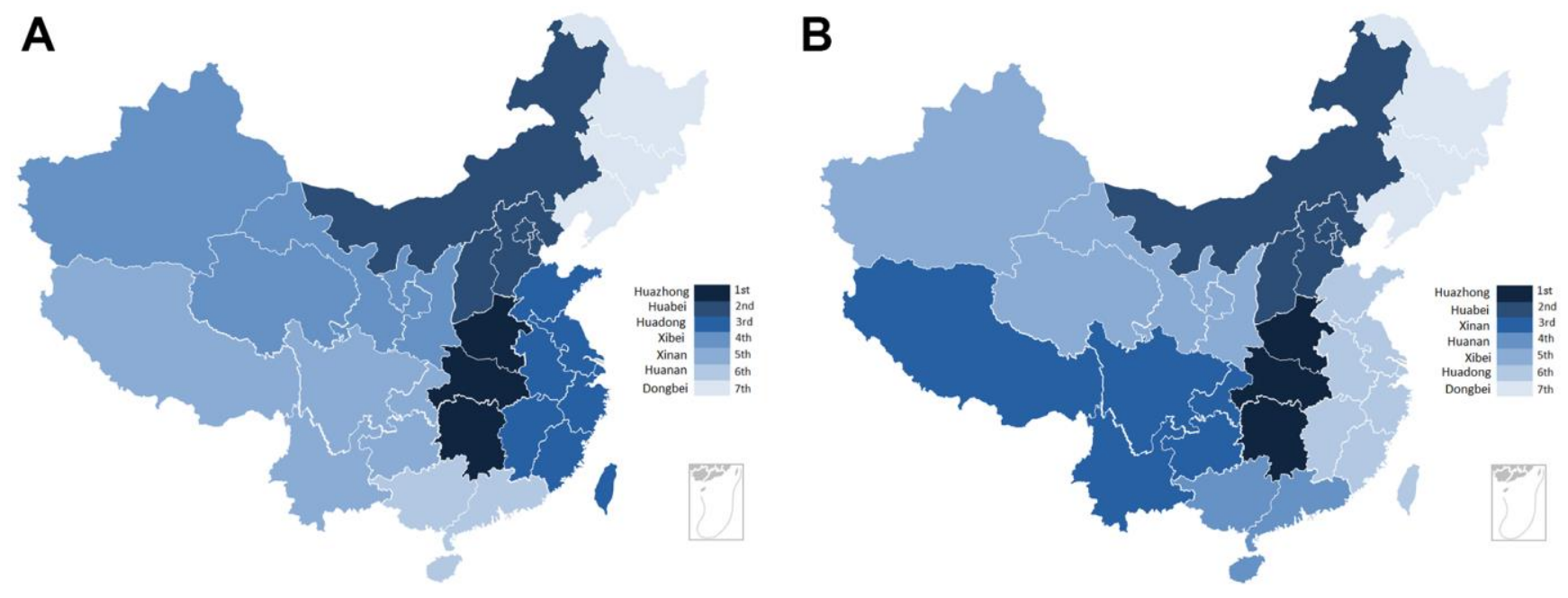

Figure 2. The distribution of $\boldsymbol{H}$. pylori infection rate for gastric cancer and population in each province. (A) The regional distribution of $H$. pylori infection for population in China. (B) The regional distribution of $H$. pylori infection for gastric cancer in China. 
Table 1. Main combined results of non-genetic factors based on fixed or random.

\begin{tabular}{|c|c|c|c|c|c|c|c|}
\hline Factors & $\begin{array}{l}\text { Case } \\
\text { n/N }\end{array}$ & $\begin{array}{c}\begin{array}{c}\text { Control } \\
\text { n/N }\end{array} \\
\end{array}$ & OR (95CI\%) & $P$ & $Z$ & Model & Studies \\
\hline \multicolumn{8}{|l|}{ Gastric cancer } \\
\hline$H p$-infection & 29728/49542 & $30896 / 62375$ & $1.62(1.47,1.79)$ & $<0.001$ & 9.81 & Random & 153 \\
\hline Smoking & $49978 / 111107$ & $59897 / 142863$ & $1.28(1.22,1.34)$ & $<0.001$ & 9.01 & Random & 286 \\
\hline Drinking & $36481 / 100199$ & $42928 / 129380$ & $1.29(1.23,1.37)$ & $<0.001$ & 8.79 & Random & 253 \\
\hline Family history & $3068 / 40960$ & $7759 / 52405$ & $1.87(1.81,1.93)$ & $<0.001$ & 31.54 & Random & 112 \\
\hline Stomach disease & $3834 / 12784$ & 2717/19727 & $2.93(2.32,2.71)$ & $<0.001$ & 9.28 & Random & 38 \\
\hline High salt diet & $3600 / / 7138$ & $4651 / 11921$ & $1.74(1.64,1.86)$ & $<0.001$ & 15.17 & Random & 31 \\
\hline Pickled food & $2952 / 5416$ & $3540 / 8164$ & $2.21(2.03,2.38)$ & $<0.001$ & 18.17 & Random & 28 \\
\hline Fast eating & $2650 / 5350$ & $2583 / 7402$ & $1.83(1.71,2.01)$ & $<0.001$ & 14.13 & Random & 18 \\
\hline Irregular meals & $3040 / 8449$ & $3910 / 12107$ & $1.71(1.62,1.91)$ & $<0.001$ & 12.86 & Random & 28 \\
\hline Edible hot food & $2479 / 5593$ & $3349 / 8720$ & $2.37(1.66,2.81)$ & $<0.001$ & 5.73 & Random & 20 \\
\hline Smoked and frying & $744 / 3708$ & $1191 / 5677$ & $1.99(1.46,2.70)$ & $<0.001$ & 4.41 & Random & 15 \\
\hline Spicy diet & $1177 / 3612$ & $1022 / 4522$ & $1.73(1.16,2.63)$ & 0.008 & 2.97 & Random & 12 \\
\hline Mental depression & $1990 / 5909$ & $1631 / 7333$ & $1.82(1.34,2.46)$ & $<0.001$ & 3.87 & Random & 19 \\
\hline BMI & $2866 / 10654$ & $5323 / 13475$ & $0.79(0.53,1.21)$ & 0.21 & 1.22 & Random & 23 \\
\hline Hypertension & $2020 / 8493$ & $2236 / 8963$ & $0.95(0.88,1.01)$ & 0.10 & 1.52 & Fixed & 24 \\
\hline Diabetes & $845 / 8283$ & $1082 / 8364$ & $0.76(0.68,0.84)$ & $<0.001$ & 5.14 & Fixed & 23 \\
\hline \multicolumn{8}{|l|}{ Non-cardiac Cancer } \\
\hline$H p$-infection & $559 / 1035$ & $925 / 1979$ & $1.46(1.24,1.72)$ & $<0.001$ & 4.59 & Fixed & 6 \\
\hline Smoking & $1376 / 2693$ & $2335 / 4662$ & $1.24(1.12,1.37)$ & $<0.001$ & 4.15 & Fixed & 13 \\
\hline Drinking & $2384 / 6799$ & $3231 / 10271$ & $1.39(1.09,1.77)$ & 0.008 & 2.65 & Random & 12 \\
\hline Family history & $418 / 2060$ & $612 / 3918$ & $3.28(1.75,6.13)$ & $<0.001$ & 3.72 & Random & 10 \\
\hline Irregular meals & $191 / 417$ & $97 / 490$ & $3.15(1.59,6.24)$ & 0.001 & 3.30 & Random & 3 \\
\hline \multicolumn{8}{|l|}{ Cardiac Cancer } \\
\hline$H p$-infection & $897 / 1345$ & $1178 / 2282$ & $1.80(1.55,2.09)$ & $<0.001$ & 0.14 & Fixed & 5 \\
\hline Smoking & $3741 / 7476$ & $5583 / 12650$ & $1.36(1.15,1.61)$ & $<0.001$ & 3.53 & Random & 24 \\
\hline Drinking & $1697 / 5445$ & $2277 / 9529$ & $1.45(1.29,1.63)$ & $<0.001$ & 6.37 & Random & 18 \\
\hline Family history & $529 / 1864$ & $596 / 2852$ & $2.46(1.25,4.85)$ & 0.009 & 2.61 & Random & 5 \\
\hline
\end{tabular}

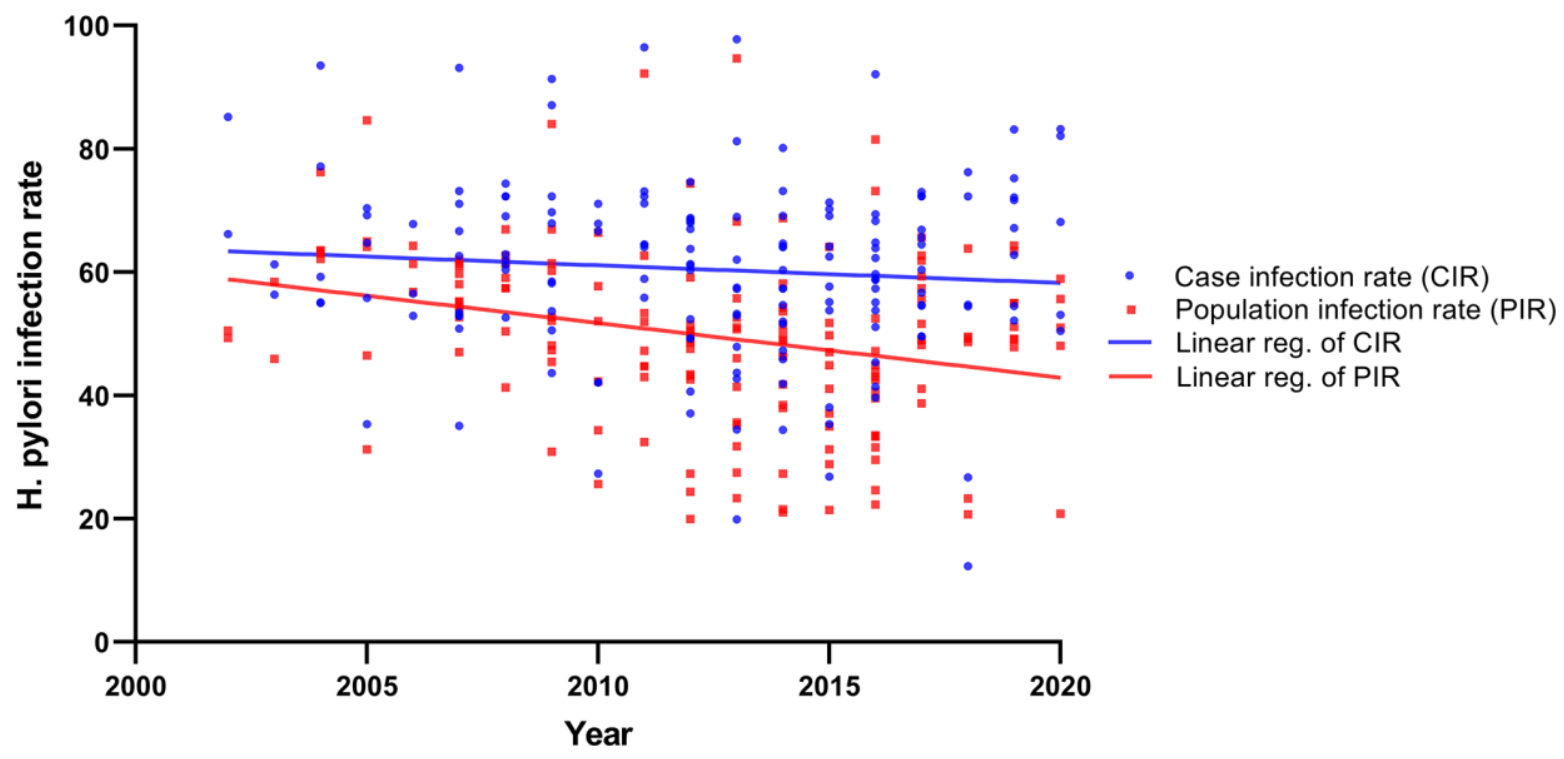

Figure 3. The linear regression analysis showed that from 2000 to $2020, \mathrm{H}$. pylori infection rate in gastric cancer and population. 
Table 2. Meta-analysis results: genetic variants significantly associated with gastric cancer risk with a high or intermediate level of summary evidence.

\begin{tabular}{|c|c|c|c|c|c|c|c|c|c|c|c|c|}
\hline \multirow{2}{*}{ Gene } & \multirow{2}{*}{ Variant ID } & \multirow{2}{*}{ Chr } & \multirow{2}{*}{$\begin{array}{l}\text { Risk } \\
\text { allele }\end{array}$} & \multirow{2}{*}{$\begin{array}{l}\text { RAF of } \\
\text { control }\end{array}$} & \multirow{2}{*}{ Participants } & \multirow{2}{*}{ OR $(95 \% C I)$} & \multirow{2}{*}{$P$-Value } & \multirow{2}{*}{$\begin{array}{c}\text { Venice } \\
\text { criteria }^{\text {a }}\end{array}$} & \multirow{2}{*}{ Evidence level $^{\mathbf{b}}$} & \multirow{2}{*}{$\begin{array}{c}\text { FPRP } \\
(0.1)\end{array}$} & \multirow{2}{*}{$\begin{array}{c}\text { FPRP } \\
(0.01)\end{array}$} & \multirow{2}{*}{$\begin{array}{c}\text { FPRP } \\
(0.001)\end{array}$} \\
\hline & & & & & & & & & & & & \\
\hline$C O X-2$ & rs 20417 & 1 & $\mathrm{C}$ & 0.044 & 1237 & $1.48(1.04,2.11)$ & 0.03 & $\mathrm{ABB}$ & Intermediate & 0.356 & 0.859 & 0.954 \\
\hline$I L-17 A$ & rs2275913 & 6 & A & 0.386 & 9335 & $1.28(1.14,1.44)$ & $<0.001$ & $\mathrm{ABA}$ & Intermediate & 0.001 & 0.007 & 0.065 \\
\hline$I L-17 A$ & rs8193036 & 4 & $\mathrm{~T} / \mathrm{CT}$ & 0.420 & 6120 & $1.13(1.01,1.26)$ & 0.03 & $\mathrm{ABA}$ & Intermediate & 0.200 & 0.734 & 0.965 \\
\hline$T G F B R 2$ & rs3773651 & 3 & G & 0.311 & 2923 & $1.40(1.22,1.61)$ & $<0.001$ & $\mathrm{ABA}$ & Intermediate & 0.051 & 0.371 & 0.856 \\
\hline$I L-10$ & rs1800896 & 1 & $\mathrm{G} / \mathrm{TT}$ & 0.056 & 2534 & $4.40(1.36,12.62)$ & 0.02 & BBB & Intermediate & 0.321 & 0.586 & 0.940 \\
\hline$V D R$ & rs731236 & 12 & $\mathrm{~T}$ & 0.936 & 4202 & $1.61(1.32,1.96)$ & $<0.001$ & $\mathrm{AAB}$ & Intermediate & 0.000 & 0.001 & 0.011 \\
\hline MTHFR & rs1801133 & 1 & $\mathrm{~T}$ & 0.410 & 7432 & $1.19(1.31,1.27)$ & $<0.001$ & $\mathrm{ABB}$ & Intermediate & 0.000 & 0.000 & 0.000 \\
\hline NAT2 & rs1799930 & 8 & A & 0.171 & 3274 & $1.43(1.27,1.62)$ & $<0.001$ & $\mathrm{AAB}$ & Intermediate & 0.000 & 0.000 & 0.000 \\
\hline NAT2 & rs1799929 & 8 & $\mathrm{~T}$ & 0.119 & 3274 & $2.17(1.58,2.98)$ & $<0.001$ & $\mathrm{ABB}$ & Intermediate & 0.000 & 0.000 & 0.000 \\
\hline NAT2 & & 8 & Slow & 0.084 & 3275 & $2.13(1.71,2.64)$ & $<0.001$ & $\mathrm{ABA}$ & Intermediate & 0.000 & 0.000 & 0.000 \\
\hline GSTM1 & & 1 & Null & 0.488 & 9971 & $1.32(1.21,1.43)$ & $<0.001$ & $\mathrm{BBB}$ & Intermediate & 0.000 & 0.000 & 0.000 \\
\hline GSTT1 & & 2 & Null & 0.476 & 7747 & $1.25(1.07,1.45)$ & 0.004 & $\mathrm{ABA}$ & Intermediate & 0.025 & 0.243 & 0.764 \\
\hline PLCE1 & rs2274223 & 10 & A & 0.226 & 9710 & $1.30(1.23,1.37)$ & $<0.001$ & AAA & High & 0.000 & 0.000 & 0.000 \\
\hline PLCE1 & rs3765524 & 10 & $\mathrm{~T}$ & 0.206 & 1950 & $1.31(1.19,1.44)$ & $<0.001$ & $\mathrm{BBB}$ & Intermediate & 0.006 & 0.067 & 0.418 \\
\hline PRKAAI & rs13361707 & 5 & $\mathrm{C}$ & 0.477 & 13743 & $1.42(1.35,1.48)$ & $<0.001$ & $\mathrm{ABA}$ & Intermediate & 0.001 & 0.008 & 0.077 \\
\hline$P S C A$ & rs2294008 & 8 & $\mathrm{~T}$ & 0.276 & 10202 & $1.19(1.12,1.27)$ & $<0.001$ & $\mathrm{ABA}$ & Intermediate & 0.000 & 0.000 & 0.000 \\
\hline$P S C A$ & rs2976392 & 8 & A & 0.243 & 7316 & $1.13(1.05,1.22)$ & $<0.001$ & AAA & High & 0.000 & 0.002 & 0.023 \\
\hline MUC1 & rs4072037 & 1 & A & 0.824 & 5521 & $1.31(1.21,1.43)$ & $<0.001$ & AAA & High & 0.000 & 0.000 & 0.001 \\
\hline$X R C C 1$ & rs1799782 & 19 & $\mathrm{~T}$ & 0.276 & 7770 & $1.40(1.22,1.61)$ & $<0.001$ & BBA & Intermediate & 0.000 & 0.000 & 0.002 \\
\hline$X R C C 1$ & rs 25487 & 19 & A & 0.292 & 6887 & $1.11(1.04,1.20)$ & 0.004 & $\mathrm{ABA}$ & Intermediate & 0.001 & 0.009 & 0.082 \\
\hline$X R C C 3$ & rs 861539 & 14 & $\mathrm{~T}$ & 0.141 & 3054 & $1.29(1.12,1.50)$ & $<0.001$ & $\mathrm{BAB}$ & Intermediate & 0.097 & 0.243 & 0.779 \\
\hline ERCC5 & rs751402 & 13 & A & 0.325 & 3899 & $1.21(1.10,1.33)$ & $<0.001$ & $\mathrm{BAB}$ & Intermediate & 0.003 & 0.035 & 0.269 \\
\hline
\end{tabular}

aVenice criteria: A (high), B (moderate), C (weak) credibility for three parameters (amount of evidence, heterogeneity and bias; see text for more details); blevel of evidence: overall level of summary evidence according to the Venice criteria. Chr, chromosome; RAF, Risk Allele Frequency of the control; FPRP, false positive report probability (three levels of prior probability, see text for more details); HP, Helicobacter pylori; LL, 95\% lower level; sOR, summary OR; UL, 95\% upper level.

The association strength $(O R)$ of 22 SNPs with gastric cancer and the average risk of population were shown in Table 3, a total of 4,194,304 combinations were generated by random combination. The relationship between the combined $O R$ and frequency of SNP was shown in Figure $5 \mathrm{C}$, and each genotype exists as a categorical variable in the population. Thus, each possible combination can be represented in a 22-dimensional form, such as $\{X X X X X X X X X X X X X X X X X X X X X X\}$, representing a combination of genotypes containing all pathogenicity. Obviously, the cumulative frequency of gastric cancer risk was highly correlated with the combined $O R$ value (Figure 5C). After logarithmic transformation, Q-Q plot showed that the $O R$ value corresponding to the accumulation frequency conforms to the normal distribution Figure 5D.

Based on the above signifcant associations, Attributable Risk Percentage $(A R P)$ and Population Attributable Risk Percentage (PARP) for non-genetic factors and 22 SNPs were calculated and presented in Tables 4,5 . For nongenetic factors, the top three for ARP were $65.87 \%$ (stomach disease),54.75\% (pickled food), and $49.75 \%$ (smoked and frying). For PARP were $34.24 \%$ (edible hot food), $34.22 \%$ (pickled food) and $23.66 \%$ (H. pylori infection). On the basis of $A R P$ and $P A R P$ associated with SNPs of gastric cancer, the top three for ARP were $53.91 \%$ (NAT2, rs1799929), 53.05\% (NAT2 phenotype), and $42.85 \%$ (IL-10, rs 1800896). For PARP (Chinese Han in Beijing, CHB) were $36.96 \%$ (VDR, rs731236), 25.58\% (TGFBR2, rs3773651) and 20.56\%(MUC1, rs4072037).

\section{DISCUSSION}

\section{Non-genetic factors}

\section{H. pylori infection}

The prevalence of $H$. pylori infection has declined globally, however, the prevalence of gastric cancer remains high in many subgroups and geographic regions [16]. Numerous studies have confirmed that $H$. pylori is an undisputed cause of gastric cancer [17]. It is considered to be one of the major risk factors for gastric cancer $[18,19] . H$. pylori is estimated that $H$. pylori infection accounts for $65 \%$ to $80 \%$ of gastric cancer, and about 660,000 new cases of gastric cancer occur 
Table 3. Association between the genetic variants and risk of gastric cancer in different comparisons.

\begin{tabular}{|c|c|c|c|c|c|}
\hline \multirow{2}{*}{ Gene rs\# } & Per-allele & Heterozygous & Homozygous & Dominant model & Recessive model \\
\hline & OR(95\%CI) & OR(95\%CI) & OR(95\%CI) & OR(95\%CI) & OR(95\%CI) \\
\hline COX-2 rs20417 & $1.48(1.04,2.11)$ & $1.48(1.03,2.15)$ & $3.74(0.15,92.29)$ & $1.51(1.05,2.19)$ & $0.69(0.48,1.01)$ \\
\hline$I L-17 A$ rs2275913 & $1.28(1.14,1.44)$ & $1.23(1.12,1.35)$ & $1.65(1.29,2.11)$ & $1.30(1.19,1.42)$ & $1.45(1.16,1.82)$ \\
\hline IL-17A 8193036 & $1.03(0.95,1.12)$ & $1.13(1.01,1.25)$ & $0.92(0.76,1.12)$ & $1.09(0.99,1.21)$ & $0.87(0.72,1.06)$ \\
\hline TGFBR2 rs 3773651 & $1.40(1.22,1.61)$ & $1.42(0.89,2.26)$ & $1.99(1.26,3.12)$ & $1.80(1.15,2.82)$ & $1.45(1.23,1.69)$ \\
\hline$I L-10 \mathrm{rs} 1800896$ & $1.75(0.89,3.41)$ & $2.04(0.86,4.20)$ & $4.40(1.36,12.62)$ & $1.39(0.95,1.83)$ & $3.99(1.23,11.28)$ \\
\hline$V D R \operatorname{rs} 731236$ & $1.61[1.32,1.96]$ & $0.60[0.49,0.74]$ & $1.23(0.41,3.66)$ & $0.60[0.49,0.74]$ & $1.17(0.39,3.48)$ \\
\hline MTHFR $\operatorname{rs} 1801133$ & $1.19(1.13,1.27)$ & $1.32(1.19,1.45)$ & $1.36(1.19,1.53)$ & $1.33(1.21,1.46)$ & $1.18(1.07,1.32)$ \\
\hline NAT2 rs1799929 & $2.17(1.58,2.98)$ & $2.18(1.43,3.31)$ & $6.92(3.79,12.63)$ & $2.38(1.57,3.61)$ & $5.76(3.14,10.55)$ \\
\hline NAT2 rs1799930 & $1.43(1.27,1.62)$ & $1.15(0.99,1.35)$ & $2.85(2.05,3.97)$ & $1.33(1.15,1.53)$ & $2.72(1.96,3.78)$ \\
\hline NAT2 phenotype $\mathrm{a}^{\mathrm{a}}$ & $2.13(1.71,2.64)$ & - & - & - & - \\
\hline GSTM1 1p13.3 ${ }^{\mathrm{b}}$ & $1.32(1.21,1.43)$ & - & - & - & - \\
\hline GSTT1 22q11.23c & $1.25(1.04,1.45)$ & - & - & - & - \\
\hline PLCE1 rs 2274223 & $1.30(1.23,1.37)$ & $1.22(1.05,1.42)$ & $1.64(1.37,1.91)$ & $1.70(1.00,2.86)$ & $1.40(1.03,1.90)$ \\
\hline PLCE1 rs3765524 & $1.31(1.19,1.44)$ & $1.37(1.13,1.65)$ & $1.37(0.88,21.4)$ & $1.37(1.14,1.64)$ & $1.22(0.79,1.90)$ \\
\hline PRKAA1 rs 13361707 & $1.42(1.35,1.48)$ & $1.50(1.37,1.63)$ & $2.03(1.84,2.23)$ & $1.66(1.53,1.80)$ & $1.53(1.42,1.66)$ \\
\hline PSCA rs2294008 & $1.19(1.12,1.27)$ & $1.30(1.20,1.42)$ & $1.19(0.86,1.64)$ & $1.30(1.13,1.49)$ & $0.92(0.81,1.06)$ \\
\hline PSCA rs2976392 & $1.13(1.05,1.22)$ & $1.24(1.13,1.37)$ & $1.12(0.94,1.34)$ & $1.22(1.12,1.34)$ & $1.02(0.86,1.20)$ \\
\hline MUC1 rs4072037 & $1.31(1.21,1.43)$ & $0.98(0.72,1.33)$ & $1.35(1.00,1.82]$ & $1.24(0.92,1.66)$ & $1.31(1.06,1.61]$ \\
\hline XRCC1 rs 1799782 & $1.40(1.22,1.61)$ & $1.44(1.23,1.68)$ & $1.64(1.39,1.93)$ & $1.51(1.28,1.78)$ & $1.45(1.01,2.07)$ \\
\hline$X R C C 1$ rs 25487 & $1.11(1.04,1.20)$ & $1.22(1.10,1.34)$ & $1.11(0.93,1.32)$ & $1.20(1.09,1.32)$ & $1.00(0.85,1.19)$ \\
\hline$X R C C 3$ rs 861539 & $1.29(1.12,1.50)$ & $1.30(1.09,1.56)$ & $1.74(1.15,2.63)$ & $1.33(1.12,1.58)$ & $1.33(0.89,1.99)$ \\
\hline ERCC5 rs 751402 & $1.21(1.10,1.33)$ & $1.20(1.05,1.38)$ & $1.48(1.20,1.82)$ & $1.25(1.10,1.43)$ & $1.34(1.11,1.64)$ \\
\hline
\end{tabular}

${ }^{a}$ The NAT2 rapid and slow acetylator phenotypes; ${ }^{b, c}$ Null versus Normal.

worldwide each year [20, 21]. The main risk factor for intestinal metaplasia, chronic atrophic gastritis and gastric adenocarcinoma (GCA) is H. pylori, which colonizes the human stomach [22]. Studies in Asian countries have shown a high positive correlation between $H$. pylori infection and GCA, while other studies in Western countries have not found a correlation or even a reverse association $[23,24]$.

In this study, we provided evidence from 119,117 Chinese participants for a positive association between gastric cancer and $H$. pylori. For gastric cancer, summary $O R$ was 1.62 (95\% CI: 1.47-1.79), greater in cardiac gastric cancer $(O R=1.80 ; 95 \%$ CI 1.55-2.09) than in non-cardiac gastric cancer $(O R=1.46 ; 95 \% C I$ : 1.24-1.72). The analysis of time trend of $H$. pylori infection was consistent with the latest systematic review and meta-analysis [25]. However, it is also estimated that $89 \%$ of non-cardia gastric cancer cases are due to this infection in American [26]. This may be related to the genetic background and geographic area of the ethnicity.

\section{Family history}

Family history is a definite and strong risk factor for gastric cancer [27, 28]. Although most gastric cancers are sporadic, about $10 \%$ of gastric cancers have family aggregation [29]. The development of gastric cancer under the age of 50 may be accompanied by a family history [30]. The history of the gastric cancer family has increased the risk of its development, with the risk of first-degree relatives of gastric cancer cases ranging from 1.3 to 3.0 , suggesting family history of gastric cancer is an independent risk factor $[31,32]$.

The evidence of family history as a risk factor for gastric cancer has been evaluated in the present study, we combined 108 studies on the association between gastric cancer and family history in China, the results showed that the family history of gastric cancer was significantly associated with gastric cancer $(O R=1.87$; 95\% CI: 1.81-1.93), non-cardiac gastric cancer $(O R=$ $3.28 ; 95 \% C I: 1.75-6.13)$ and cardiac cancer $(O R=$ 2.46; 95\% CI: 1.25-4.85), respectively. Therefore, determining genetic parameters of subjects with a family history of gastric cancer is an important step in the correct diagnosis and treatment of the disease.

\section{Smoking and drinking}

Numerous studies have shown that the relationship between smoking and gastric cancer is not sufficient to include smoking as a risk factor for gastric cancer, but the International Agency for Research on Cancer (IARC) concluded in 2002 that there is sufficient evidence to support smoking as a risk factor for cancer [12]. This is consistent with our findings from 286 
Chinese studies, the smoking was an independent risk factor for gastric cancer $(O R=1.28$; 95\% CI: 1.22$1.34)$, non-cardiac gastric cancer $(O R=1.24 ; 95 \%$ CI: $1.12-1.37)$ and cardiac cancer $(O R=1.33 ; 95 \% C I$ : $1.12-1.57)$, respectively.

Both tobacco smoke and alcohol are established carcinogens, alcohol consumption is considered a typical carcinogenic factor in the latest list of carcinogens published by the IARC [33]. Epidemiological studies have consistently argued that high alcohol consumption is associated with an increased risk of gastric cancer and reports a strong dose-response relationships [34]. In our study, we analyzed the relationship between alcohol consumption and gastric cancer from 211,079 participants. The results indicated that alcohol consumption was positively associated with gastric
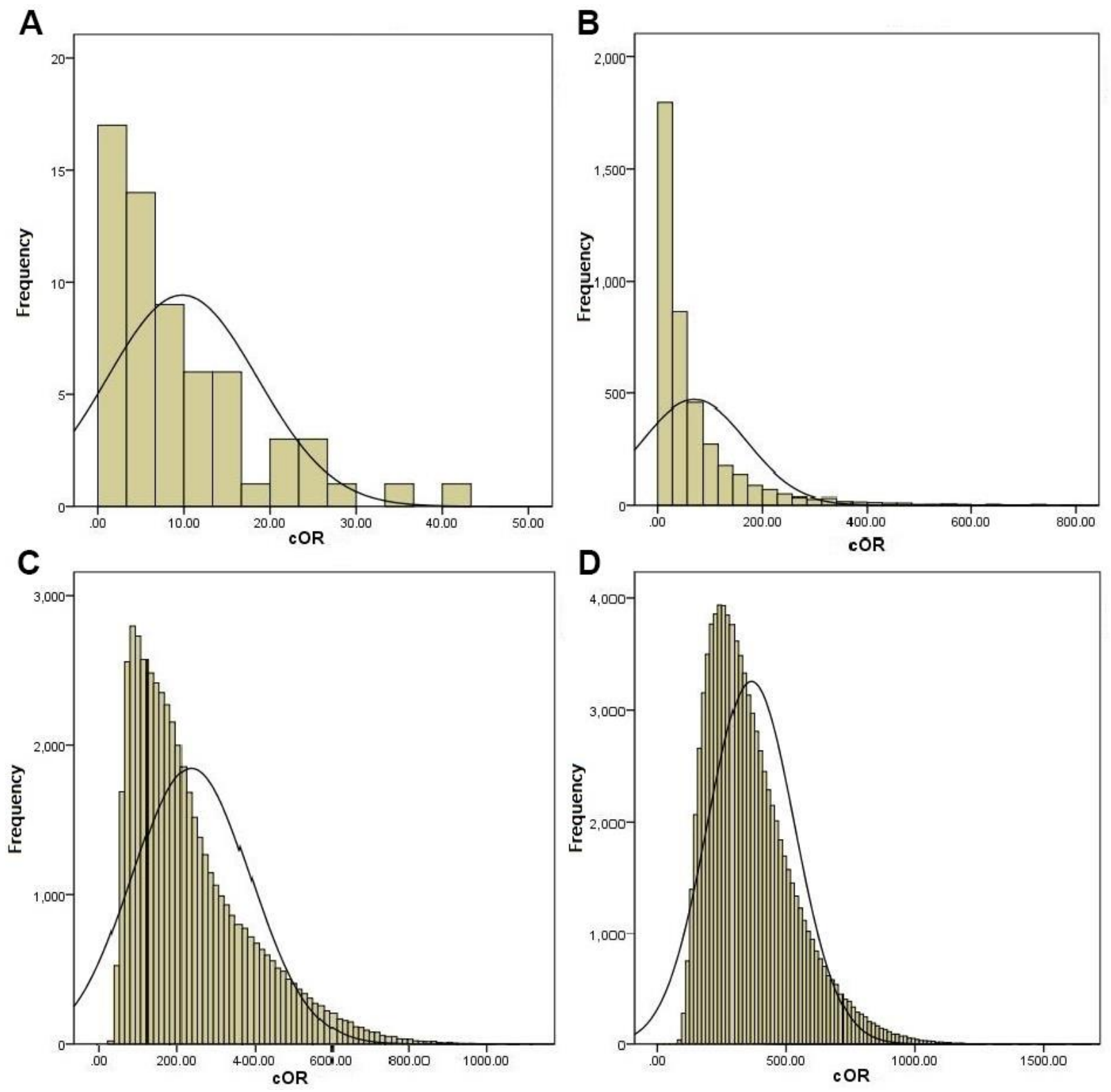

Figure 4. The distribution of genetic variants that were significantly related to the risk of gastric cancer based on the main function of genes. (A) Inflammatory related genes (COX-2 rs20417(C), IL-17A rs2275913, IL-17A rs8193036, TGFBR2 rs3773651, IL-10 rs1800896 and VDR rs731236). (B) B+Metabolic pathway related genes (MTHFR rs1801133, NAT2 rs1799930, NAT2 rs1799929, NAT2 phenotype, GSTM1 and GSTT1). (C) A+B+Signal pathway related gene (PLCE1 rs2274223, PLCE1 rs3765524, PSCA rs2294008, PSCA rs2976392, PRKAA1 rs13361707 and MUC1 rs4072037). (D) A+B+C+Base excision repair pathway related gene (XRCC1 rs1799782, XRCC1 rs25487, XRCC3 rs861539 and ERCC5 rs751402). 
cancer risk $(O R=1.29 ; 95 \% C I: 1.23-1.37)$, noncardiac gastric cancer $(O R=1.39 ; 95 \% C I: 1.09-1.77)$ and cardiac cancer $(O R=1.45 ; 95 \% C I: 1.29-1.64)$, respectively.

\section{Stomach disease}

Previous studies have shown that peptic ulcer disease, stomach and duodenal diseases have emerged or become more prevalent in Western countries in the 19th century, probably due to changes in the epidemiology of $H$. pylori infection [35]. The risk of gastric cardia cancer is related to gastroesophageal reflux disease $[12,36]$. However, the evidence does not indicate that these risk factors are associated with non-cardia cancer $[37,38]$. Our study suggested that the history of gastric diseases was strongly associated with gastric cancer $(O R=2.9,95 \% C I: 2.32-2.71)$ in Chinese population.
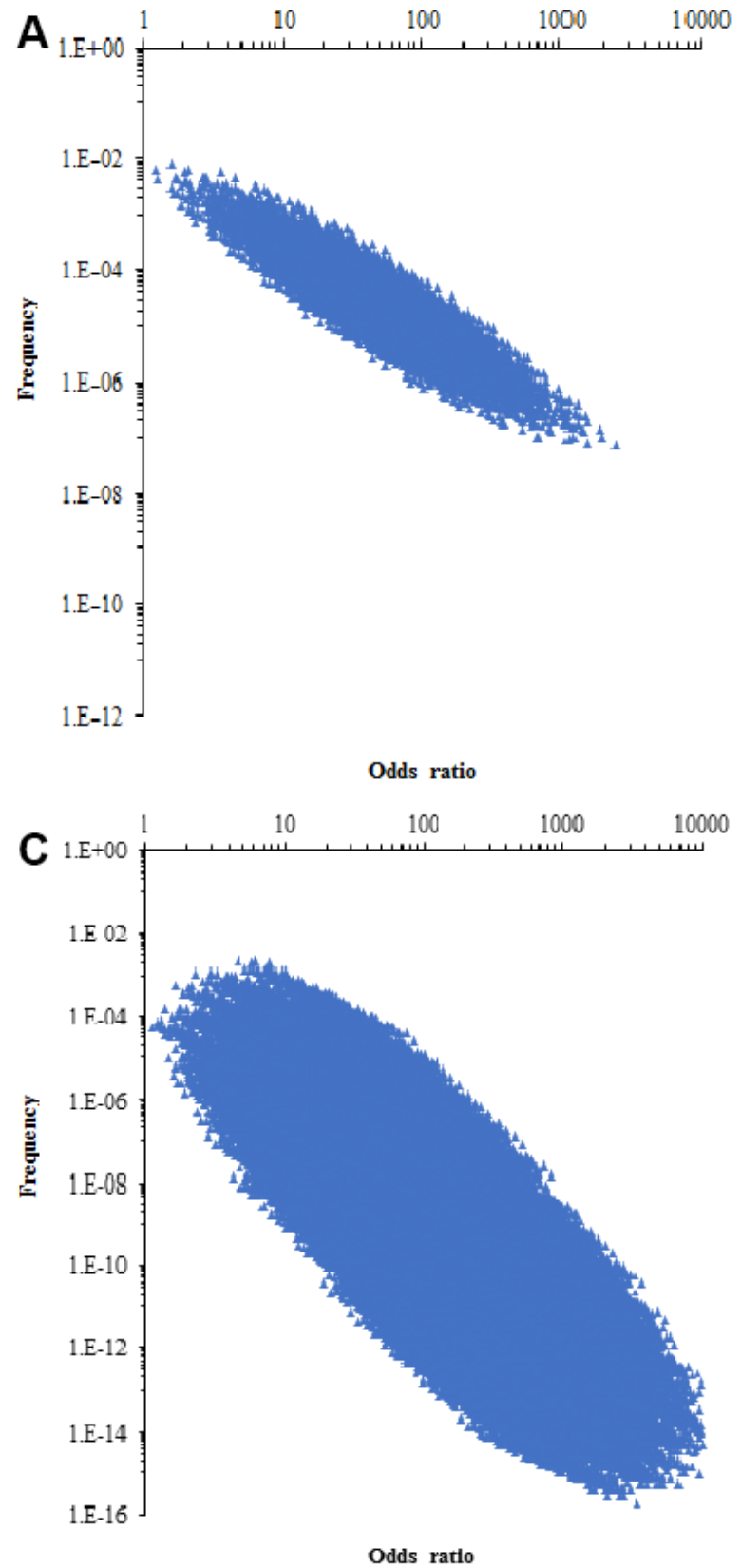

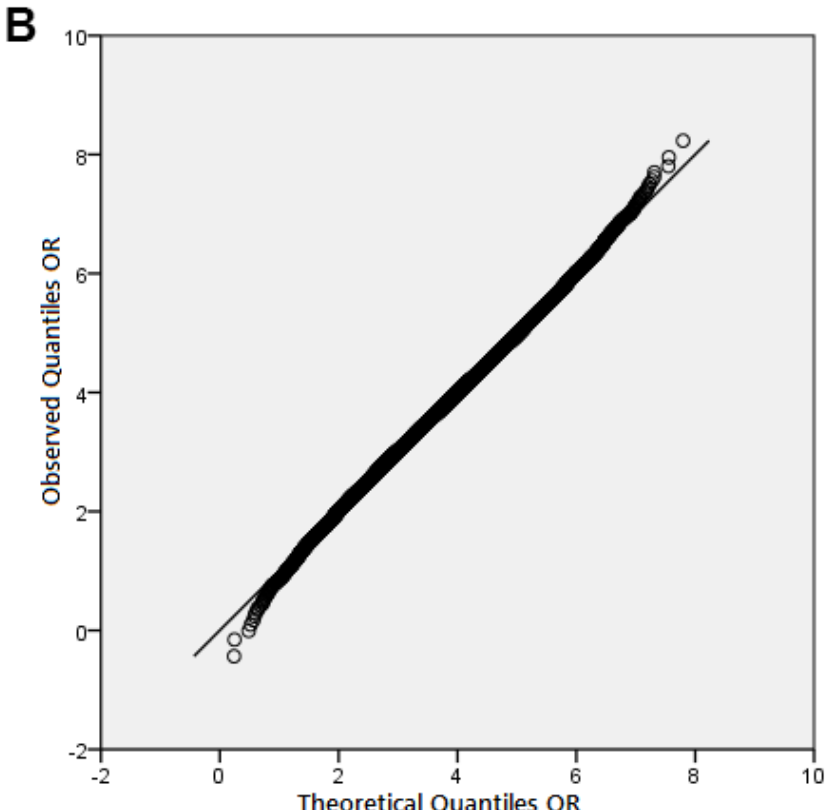

D

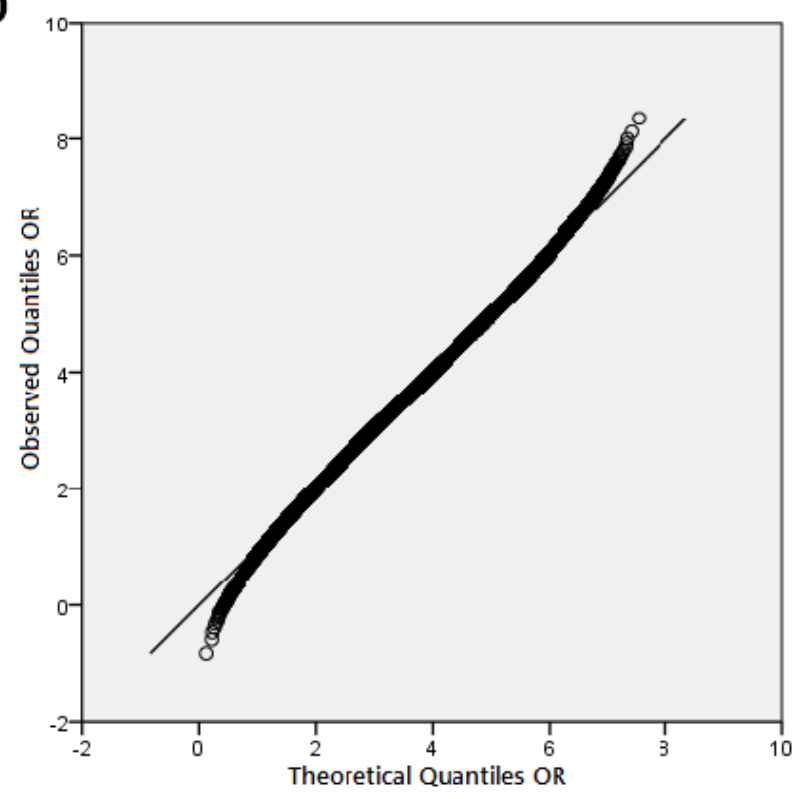

Figure 5. The combined distribution of the correlation strength and Q-Q normal distribution plot. (A) The combined distribution of the correlation strength $(O R)$ of the 13 risk factors and the accumulation frequency. (B) Q-Q normal distribution plot of non-genetic factor accumulation frequency $O R$. (C) The combined distribution of the correlation strength (OR) of the 22 SNPs and the accumulation frequency. (D) Q-Q normal distribution plot of genetic factor accumulation frequency $O R$. 
Table 4. The relationship between non-genetic factors and epidemiological effect estimation for gastric cancer.

\begin{tabular}{lcccc}
\hline \multirow{2}{*}{ Risk factors } & \multirow{2}{*}{ SOR(95\%(C) } & \multirow{2}{*}{ Risk frequency } & \multicolumn{2}{c}{ Epidemiological effect estimation } \\
\cline { 4 - 5 } & & & $\boldsymbol{A R P}(\boldsymbol{\%})$ & $\boldsymbol{P A R P ( \% )}$ \\
\hline Hp-infection & $1.62(1.47,1.79)$ & 0.50 & 38.27 & 23.66 \\
Smoking & $1.28(1.22,1.34)$ & 0.42 & 21.88 & 10.52 \\
Drinking & $1.29(1.23,1.37)$ & 0.33 & 22.48 & 8.73 \\
Family history & $1.87(1.81,1.93)$ & 0.15 & 46.52 & 11.54 \\
Stomach disease & $2.93(2.32,2.71)$ & 0.14 & 65.87 & 21.27 \\
High salt diet & $1.74(1.64,1.86)$ & 0.39 & 43.53 & 22.40 \\
Pickled food & $2.21(2.03,2.38)$ & 0.43 & 54.75 & 34.22 \\
Fast eating & $1.83(1.71,2.01)$ & 0.39 & 45.36 & 24.25 \\
Irregular meals & $1.71(1.62,1.91)$ & 0.32 & 41.52 & 34.51 \\
Edible hot food & $2.37(1.66,2.81)$ & 0.38 & 57.81 & 17.21 \\
Smoked and frying & $1.99(1.46,2.70)$ & 0.21 & 49.75 & 14.38 \\
Spicy diet & $1.73(1.16,2.63)$ & 0.23 & 42.20 & 15.28 \\
Mental depression & $1.82(1.34,2.46)$ & 0.22 & 45.05 & -3.22 \\
Diabetes & $0.76(0.68,0.84)$ & 0.13 & 31.58 & \\
\hline
\end{tabular}

$A R P$, attributable risk percentage; $P A R P$, population attribute risk percentage.

$A R P=|O R-1 / O R| \times 100 \% ; \operatorname{PARP}=|\operatorname{Pe}(O R-1) /[P e(O R-1)+1]| \times 100 \%, \quad P$ was the mutation proportion of the control group risk percentage.

Table 5. The relationship between genetic variants and epidemiological effect estimation for gastric cancer.

\begin{tabular}{|c|c|c|c|c|c|c|c|c|c|}
\hline \multirow{2}{*}{ Gene function } & \multirow{2}{*}{ Gene (Var.) } & \multirow{2}{*}{$\begin{array}{l}\text { Risk } \\
\text { allele }\end{array}$} & \multicolumn{2}{|c|}{ Risk allele frequency } & \multirow{2}{*}{ sOR } & \multirow{2}{*}{$\begin{array}{c}\text { Genetic } \\
\text { score }\end{array}$} & \multicolumn{3}{|c|}{ Epidemiological effect estimation } \\
\hline & & & Control & CHB & & & $\operatorname{ARP}(\%)$ & $\operatorname{PARP}^{\text {Control }}(\%)$ & $\operatorname{PARP}^{\mathrm{CHB}}(\%)$ \\
\hline \multirow{6}{*}{ Inflammation } & COX-2 (rs20417) & $\mathrm{C}$ & 0.04 & 0.05 & 1.48 & 1.05 & 32.43 & 2.08 & 2.50 \\
\hline & IL-17A (rs2275913) & A & 0.39 & 0.49 & 1.28 & 1.29 & 21.88 & 9.76 & 12.07 \\
\hline & IL-17A (rs8193036) & $\mathrm{C}$ & 0.42 & 0.31 & 1.13 & 1.08 & 11.50 & 5.21 & 3.88 \\
\hline & TGFBR2 (rs3773651) & G & 0.78 & 0.86 & 1.4 & 1.81 & 28.57 & 23.83 & 25.58 \\
\hline & IL-10 (rs1800896) & G & 0.06 & 0.03 & 1.75 & 1.05 & 42.86 & 4.06 & 2.49 \\
\hline & VDR (rs731236) & $\mathrm{T}$ & 0.94 & 0.96 & 1.61 & 2.52 & 37.89 & 36.35 & 36.96 \\
\hline \multirow{6}{*}{ Metabolism } & MTHFR (rs1801133) & $\mathrm{T}$ & 0.41 & 0.47 & 1.19 & 1.18 & 15.97 & 7.22 & 8.13 \\
\hline & NAT2 (rs1799930) & A & 0.17 & 0.20 & 1.43 & 1.18 & 30.07 & 6.85 & 7.88 \\
\hline & NAT2 (rs1799929) & $\mathrm{T}$ & 0.12 & 0.00 & 2.17 & 1.01 & 53.92 & 12.23 & 0.34 \\
\hline & NAT2 phenotype & Slow & 0.08 & 0.08 & 2.13 & 1.20 & 53.05 & 8.70 & 8.70 \\
\hline & GSTM1 & Null & 0.49 & 0.49 & 1.32 & 1.34 & 24.24 & 13.51 & 13.51 \\
\hline & GSTT1 & Null & 0.48 & 0.48 & 1.25 & 1.25 & 20.00 & 10.64 & 10.64 \\
\hline \multirow{3}{*}{ Signal transduction } & PLCE1 (rs2274223) & A & 0.23 & 0.19 & 1.3 & 1.12 & 23.08 & 6.35 & 5.37 \\
\hline & PLCE1 (rs3765524) & $\mathrm{T}$ & 0.21 & 0.19 & 1.31 & 1.12 & 23.66 & 6.01 & 5.54 \\
\hline & $\begin{array}{c}\text { PRKAA1 } \\
\text { (rs13361707) }\end{array}$ & $\mathrm{C}$ & 0.48 & 0.50 & 1.42 & 1.46 & 29.58 & 16.69 & 17.21 \\
\hline \multirow{3}{*}{ Apoptosis/Proliferation } & PSCA (rs2294008) & $\mathrm{C}$ & 0.28 & 0.25 & 1.19 & 1.10 & 15.97 & 4.99 & 4.49 \\
\hline & PSCA (rs2976392) & A & 0.28 & 0.24 & 1.13 & 1.06 & 11.50 & 3.55 & 3.06 \\
\hline & MUC1 (rs4072037) & A & 0.82 & 0.84 & 1.31 & 1.58 & 23.66 & 20.36 & 20.56 \\
\hline \multirow{4}{*}{ Excision repair } & XRCC1 (rs1799782) & $\mathrm{T}$ & 0.28 & 0.29 & 1.4 & 1.24 & 28.57 & 9.95 & 10.28 \\
\hline & XRCC1 (rs25487) & A & 0.29 & 0.25 & 1.11 & 1.06 & 9.91 & 3.11 & 2.70 \\
\hline & XRCC3 (rs861539) & $\mathrm{T}$ & 0.14 & 0.07 & 1.29 & 1.04 & 22.48 & 3.92 & 1.93 \\
\hline & ERCC5 (rs751402) & A & 0.33 & 0.35 & 1.21 & 1.15 & 17.36 & 6.39 & 6.93 \\
\hline
\end{tabular}

CHB Han Chinese in Beijing, China; $A R P$, attributable risk percentage; $P A R P$, population attribute risk percentage; $A R P$ $=|\mathrm{OR}-1 / \mathrm{OR}| \times 100 \%$.

$P A R P=|P e(O R-1) /[P e(O R-1)+1]| \times 100 \%, P$ was the mutation proportion of the control group risk percentage.

Genetic score $=(1-p)^{2}+2 p(1-p) O R+p^{2} O R^{2}, p$ was the risk allele frequency. 


\section{Diet}

Studies have shown that smoked meat and saltpreserved foods can cause cancer, and large intakes increase the risk of $H$. pylori infection $[39,40]$. Bacon produces $\mathrm{N}$-nitroso compounds associated with gastric cancer, and many epidemiological and experimental studies support this hypothesis [41, 42], including our findings $(O R=1.99 ; \quad 95 \% C I: 1.46-2.70$ for smoked or frying meat, $O R=2.21,95 \% C I: 2.03-2.38$ for pickled food).

A large cohort study in South Korea showed that people who eat more salty foods have a higher risk of gastric cancer, because salty foods can directly damage the gastric mucosa and cause gastritis [16]. This is consistent with the results of our research $(O R=1.74$, 95\% CI: 1.64-1.86).

Bulgarian researchers have found that during the economic crisis, radiologically recorded gastroduodenal ulcers have increased, and they believe that no meals and continuous smoking are the causes of ulcers [43]. The recent studies showed that frequent deviation in meal timing over a prolonged period appears associated with increased risk of $H$. pylori infection and gastritis [44]. Based on these considerations, we conducted a quantitative analysis of the relationship between irregular diet and gastric cancer in China. The results showed that both irregular diet and fast diet were independent risk factors for gastric cancer $(O R=1.71,95 \%$ CI: $1.62-1.91$ for irregular meals and $O R=1.83,95 \% C I$ : $1.71-2.01$ for fast eating).

An epidemiological survey in India shows that spicy diet is an independent risk factor for gastric cancer [45]. The impact of dietary habits on gastric cancer showed that regular consumption of fried or grilled food and consumption of spicy food were important factors associated with gastric cancer in males and females [46]. In Chinese population, our research further confirmed that spicy diet $(O R=1.73,95 \%$ CI: 1.16-2.63) and edible hot food $(O R=2.37,95 \% \mathrm{CI}: 1.66-2.81)$ are significantly associated with gastric cancer. According to the above epidemiological evidence, dietary habit was an important factor contributing to gastric cancer.

\section{Mental depression}

Studies have shown that leptin and its receptor (leprb) are independent factors for the poor prognosis of patients with gastric cancer and suggest that leptin-leperbis is a necessary factor for the action of antidepressants [47]. Depression is a common symptom in patients with gastric cancer and a potential marker for poor prognosis and clinical stage of advanced cancer [48]. The study found Leptin-leprb plays an important role in the pathogenesis and depression of gastric cancer Leptin-leprb may be a potential diagnostic marker and therapeutic target for gastric cancer. We found a significant statistical association between mental depression and gastric cancer through quantitative combine of observational epidemiological studies $(O R=1.82,95 \%$ CI: 1.34-2.46).

\section{Other factors}

The risk of cardia cancer is related to obesity and gastroesophageal reflux disease [36]. Epidemiological and evidence-based medicine studies have similar results. People with BMI than $30 \mathrm{~kg} / \mathrm{m}^{2}$ have a significantly increased risk of cardiac cancer [49, 50]. However, we did not find the association between gastric cancer and obesity $(O R=0.79,95 \% C I$ : 0.53 1.21). Meanwhile, we did not find a statistically significant association between hypertension and gastric cancer $(O R=0.95,95 \% C I: 0.88-1.01)$. It is worth noting that we found that the risk of gastric cancer was lower in the diabetic population than in the general population $(O R=0.76,95 \%$ CI: $0.68-0.84)$. This may be due to the change of diet structure and living habits in patients with diabetes mellitus, and it is also related to taking metformin [51].

\section{Genetic risk factors}

A considerable number of patients with gastric cancer have potential genetic predisposition syndromes, especially those with a family history of early gastric cancer and other cancers [52]. Once an individual is found to have a predisposition to gastric cancer, screening or risk reduction procedure can be initiated to detect or prevent cancer early [53]. Therefore, identifying risk-related biomarkers is essential for early detection of gastric cancer. In this study, we assessed the credibility and intensity of a significant association between candidate gene SNPs and GC risk, providing comprehensive information for further research.

\section{PLCE1 rs2274223 and rs3765524}

Phospholipase C epsilon 1 (PLCE1) plays an important role in cell growth, differentiation and carcinogenesis. The rs2274223, located in exon 26 of the PLCE1, is a non-synonymous SNP that causes an amino acid to change from histidine to arginine [54]. An increasing amount of studies have begun to explore the relationship between PLCE1 rs2274223 polymorphism and susceptibility of different cancers [55]. In this study, a statistically significant association was observed in gastric cancer for rs2274233 (A vs. G: $O R$ $=1.30 ; 95 \%$ CI: $1.23-1.37$ ). This is consistent with the results of large sample published studies $[55,56]$. The rs3765524 is in exon 24 and in Y domain. GWAS found that SNPs in the PLCE1 are mainly rs2274223 A>G and rs3765524 $\mathrm{C}>\mathrm{T}$, which are common susceptibility sites for esophageal cancer and gastric cancer $[14,54,57$, 
58]. Because they are completely linkage disequilibrium (LD) $\quad\left(\mathrm{r}^{2}=1.00\right) \quad$ (http://grch37.ensembl.org/Homo sapiens/Tools/LD/Results?tl=YduaFHeCYXzsiKQX5544662), the results were basically the same (A vs. G: $O R=1.30 ; 95 \% C I: 1.22-1.38)$, and they were all the SNPs of PLCE1 in Chinese population [59].

\section{PSCA rs2976392 and rs2294008}

The prostate stem cell antigen (PSCA) gene is located on chromosome 8q24.2 and encodes a 123-amino acid cell surface protein with $30 \%$ homology to type 2 stem cell antigen (SCA-2) [60]. The PSCA polymorphism is associated with high expression of PSCA in cancer patients [61]. The T allele of PSCA rs2294008 could decrease the transcriptional activity of the PSCA promoter in gastric cell lines [62]. The rs $2976392 \mathrm{G}>\mathrm{A}$ and rs2294008 C>T polymorphisms are the most widely studied polymorphisms in the PSCA, and have been proved to be associated with an increased risk of gastric cancer [63]. LD analysis for PSCA rs2294008 and rs2976392 in Chinese Han population indicated that they have a strong LD $\quad\left(r^{2}=0.974\right)$ (http://grch37.ensembl.org/Homo_sapiens/Tools/LD/Re sults?tl=7sSPOBfXyLzee3pP-5720247). The online LD value prediction result is consistent with the published study [63]. Our findings also confirm this association (rs2976392: $\mathrm{C}$ vs. T: $\mathrm{OR}=1.13,95 \%$ CI: 1.05-1.22; rs2294008: A vs. G: $O R=1.19,95 \% C I: 1.12-1.27)$.

\section{MUC1 rs4072037}

Abnet et al. conducted a GWAS of the Chinese population in 2010 and found that the MUC1 rs4072037 polymorphism is related to gastric cancer risk [14]. In 2011, Saeki et al. performed a GWAS of gastric cancer in the Japanese population and found that the MUCI rs4072037 polymorphism gastric cancer risk [57]. In this study, the A allele was significantly associated with an increased risk of gastric cancer (A vs. G: $O R=1.31$, 95\% CI: 1.21-1.43). This is close to the GWAS result.

\section{PRKAA1 rs13361707}

The 5'-AMP activated protein kinase (AMPK) is encoded by the AMP-activated protein kinase catalytic subunit alpha-1 gene (PRKAAl) located on chromosome 5p13.1 [64]. The PRKAAl rs13361707 $\mathrm{T}>\mathrm{C}$ is the most widely studied polymorphism associated with gastric cancer risk. Previous GWASs found that the PRKAAl rs13361707 was a risk factor for non-cardiac gastric cancer in Chinese populations [15]. However, these results were not successfully replicated. In the present study, a significant relationship was revealed between the PRKAAl rs13361707 $\mathrm{T}>\mathrm{C}$ and gastric cancer susceptibility under all genetic model (C vs. T: $O R=1.42,95 \% C I: 1.35-1.48$, CT vs. TT: $O R=1.50,95 \%$ CI: $1.37-1.63$; CC vs. TT: $O R=$ 2.03, 95\% CI: $1.84-2.23$; CT+CC vs. TT: $O R=1.66$,
95\% CI: $1.53-1.80 ; \mathrm{CC}$ vs. CT+TT: $O R=1.53,95 \% C I$ : 1.42-1.66). The results are consistent with those of Jiang et al. [65].

\section{Other significant associations}

Among 22 significantly associated SNPs, the level of evidence for high and intermediate were $3(13.64 \%)$ and $19(86.36 \%)$, respectively. The above discussion mainly involved SNPs with high quality evaluation and their LD SNPs or discovered by GWAS. The remaining SNPs $\quad(I L-17 A, \quad$ rs2275913, rs8193036; IL-10, rs1800896; MTHFR, rs1801133; COX-2, rs20417; XRCC1, rs1799782, rs25487, rs861539; NAT2, rs1799929, rs1799930, phenotype; GSTM1; GSTT1; ERCC5, rs751402; TGFBR2, rs3773651; VDR, rs731236) are also significantly associated with the risk of gastric cancer.

\section{Epidemiological evaluation of risk factors}

In this study, we firstly analyzed 13 non-genetic factors risk and 22 common SNPs as each independent unit using a programming program, and analyzed the distribution of $O R$ values corresponding to each accumulation frequency. The ORs value corresponding to the accumulation frequency are in accordance with the normal distribution, and the ORs value gradually increases as the accumulation frequency decreases.

The ARP and PARP indicated the number of gastric cancers among exposed individuals that can be attributed to that exposure. Among the controllable factors, changing unreasonable eating habits and bad behaviors, it can effectively reduce the risk of gastric cancer, and has good socioeconomic benefits. On the basis of $A R P$ and PARP associated with SNPs of gastric cancer, we calculated the frequency of allele variation in the control and Chinese population, respectively, and the results were consistent. In the present study, we firstly presented the data on $A R P$ and $P A R P$ for effects of total gastric cancer-related SNPs based on the data from public databases and human genome (HapMap) project to evaluate the contribution of SNPs to the occurrence of gastric cancer.

There are some limitations should be pointed out. Among the included studies, the proportion of cohort studies was relatively low. In addition, the heterogeneity of some risk factors was high after combined analysis, which reduces the credibility of the results to a certain extent. Further, some non-genetic factors cannot be performed due to insufficient data in the stratification analysis of gastric cancer subtypes. Finally, the interaction between independent risk factors was not addressed, such as the interaction between environmental risk factors and environmental or genetic factors, and the interaction between SNP and SNP were 
ignored in the analysis of multiple gene association, interactive and additive effects are recommended for exploration in future studies.

\section{CONCLUSIONS}

In summary, we conducted the first field synopsis in Chinese population linking common non-genetic risk factors and DNA variation to summarize potential nongenetic and genetic risk factors for gastric cancer, and to evaluate their epidemiological significance. We hope that comprehensive data collection will provide a useful platform for researchers who may be responsible for the pathogenesis of gastric cancer.

\section{MATERIALS AND METHODS}

This study was conducted based on the Meta-analysis of Observational Studies in Epidemiology (MOOSE) [66], Preferred Reporting Items for Systematic Reviews and Meta-Analysis (PRISMA) guidelines [67] and the systematic review principles of molecular association studies proposed by the Human Genome Epidemiology Network (HuGENet) [68-70].

\section{Search strategy}

A systematic literature searching was implemented using PubMed, EMBASE, Cochrane Library, Web of Science, CNKI (Chinese), Wanfang (Chinese), VIP (Chinese) and CBM (Chinese) database updated to November 28, 2020. The combination terms for retrieval were keywords: "risk factor" and " $H$. pylori infection" and " $H$. pylori colonization"; "gastric" and "stomach" or "junctional and non-junctional"; "carcinoma", "tumor" and "cancer"; "polymorphism", "single nucleotide polymorphism" and its acronym "SNP", "variant", "variation"; "China" and "Chinese" and "Chinese Population". To further identify potential articles, we also manually retrieved bibliography of relevant studies that were not retrieved by literature databases, and HuGENet Phenopedia, http://www.hugenavigator.net/HuGENavigator/startPag e PhenoPedia was searched.

\section{Inclusion and exclusion criteria}

The inclusion criteria were as follows: (i) about the polymorphisms or non-genetic factors and gastric cancer risk in Chinese populations; (ii) case-control or cohort-designed study; (iii) studies with raw data or summarizing data for estimating an odds ratio (OR) with $95 \%$ confidence interval (CI); (iv) and (4) available genotype frequencies. Exclusion criteria were data published only in abstract form, with minor allele frequencies $<1 \%$ (rare variation) in the control group, sample size $<10$ cases or control group, and the genotypes of controls were not in accordance with the assumptions of HWE.

\section{Data extraction}

Data extraction was conducted independently by two authors (FJD and CHS) and discrepancies were finalized after consultation with third author (KJW). The information extracted from included studies if available: the first author's name, publication year, sample size, nations, demographics, gastric cancer subtype (gastric cancer, non-cardiac gastric cancer and cardiac cancer) and Lauren classification (intestinal, diffuse and mixed type), design of study, genotype distributions and potential risk factors $(H$. pylori infection, smoking, drinking, family history, stomach disease, high salt diet, pickled food, fast eating, irregular meals, edible hot food, smoked and frying, spicy diet, mental depression, body mass index (BMI), hypertension, diabetes). If duplicate publications using the same population were found, data from the most recent publication were included.

\section{Assessment of cumulative evidence}

To assess the credibility of each nominally statistically significant association determined by pooled analysis, we adopted the Venice standard [68, 71-73]. In short, the level of confidence is defined by the level of three parameters $(\mathrm{A}=$ strong, $\mathrm{B}=$ medium or $\mathrm{C}=$ weak $)$, the grades may be scored as follows: (1)AAA- strong evidence. (2) $\mathrm{AAB}, \mathrm{ABA}, \mathrm{ABB}, \mathrm{BAA}, \mathrm{BBA}, \mathrm{BBB}$, $\mathrm{BAB}$ - moderate evidence. (3) Rest all scores will be treated as poor, unreliable evidence. In addition to the Venice standard, we also assessed the significance findings by calculating the false positive reporting probability (FPRP) [74, 75]. In the early stage, statistically significant genetic association studies, even with large sample sizes, were well implemented, avoiding all research biases, and the probability of false positives was still high. Studies have shown that at least 95\% of the research results are statistically significant, which we call "no real correlation probability", which is FPRP.

\section{Statistical analysis}

The pooled ORs with 95\% CIs were performed by Review Manager 5.3.5 (Cochrane Collaboration, Oxford, UK) to evaluate relationship between genetic variant, potential risk factors and gastric cancer risk. For some studies, including GWAS, only per-allele $O R$ were available, and genetic modeling is carried out by calculating an allele model. For each variant or potential risk factor, a meta-analysis was performed if 
at least three data sets were available. As for GWAS, the discovery and verification phases are treated as separate data sets.

Meta-analysis used a fixed effect model ( $P$-value of heterogeneity $\left(P_{\text {heterogeneity }}\right) \geq 0.10$ or $I^{2} \leq 50 \%$ ) or a random effects model $\left(P_{\text {heterogeneity }}<0.1\right.$ and $I^{2}>50 \%$ ) based on the inter-study heterogeneity, and we obtained the distribution of observed and expected values by quantile-quantile (Q-Q) plots. The trend distributions were performed with Visual Studio 2013 (Microsoft Corporation, Redmond, USA) to explore by possible combinations and frequencies of genetic variants and potential risk factors.

The relative risk $(R R)$ of the exposed part of the population is divided into the $R R$ of the unexposed part of the population, and the relative measure of the given exposure effect $(R R)$ is obtained. If the occurrence is rare, it is approximately $R R(R R \approx O R)$, the $\mathrm{RR}$ was estimated using the summary estimates $(O R)$ calculated by the meta-analysis.

$A R P$ - and PARP as indexes were used to assess the effect of epidemiology.

$A R P=|O R-1 / O R| \times 100 \%$

$P A R P=P_{\mathrm{e}}\left|(O R-1) /\left[P_{\mathrm{e}}(O R-1)+1\right]\right| \times 100 \%$

$P_{\mathrm{e}}$ was the mutation proportion of the control group.

The population average risk (Genetic score) of single SNP was calculated based on the genotype frequency of the genetic variation in the haplotype map of the HapMap and the pooled $O R$ of the meta-analysis in the Chinese population.

Genetic score $=(1-p)^{2}+2 p(1-p) O R+p^{2} O R^{2}$

$p$ was the risk allele frequency.

The Q-Q plot is a graphical technique for determining if two data sets come from populations with a common distribution. All $P$-values were two-sided and $P<0.05$ was considered statistically significant. The sensitivity analysis and publication bias were performed using STATA 13.1 (StataCorp, College Station, TX, USA).

\section{Abbreviations}

FPRP: False-positive report probability; $A R P$ : Attributable risk percentage; PARP: Population attributable risk percentage; SNP: Single nucleotide polymorphism; GWAS: Genome wide association study; MOOSE: Meta-analysis of Observational Studies in Epidemiology; PRISMA: Preferred Reporting Items for Systematic Reviews and Meta-Analysis; $R R$ : Relative risk; OR: Odds ratios.

\section{AUTHOR CONTRIBUTIONS}

FD, CS, and KW designed the study. JS and PW performed the literature search, the selection of eligible articles. JS and FD extracted the data. LD and HY analyzed the data. KW, JZ, and FD checked the data. $\mathrm{FD}, \mathrm{JZ}$, and $\mathrm{KW}$ wrote the first draft of the manuscript. All authors were involved in the revision of the manuscript and approved the final manuscript.

\section{CONFLICTS OF INTEREST}

The authors declare that they have no conflicts of interest.

\section{FUNDING}

This work was funded by the National Natural Science Foundation of China (81373097), the National Science and Technology Major Project of China (2018ZX10302205), and the Major Project of Science and Technology in Henan Province (161100311400).

\section{REFERENCES}

1. Siegel RL, Miller KD, Jemal A. Cancer statistics, 2018. CA Cancer J Clin. 2018; 68:7-30. https://doi.org/10.3322/caac.21442 PMID:29313949

2. Torre LA, Siegel RL, Ward EM, Jemal A. Global Cancer Incidence and Mortality Rates and Trends--An Update. Cancer Epidemiol Biomarkers Prev. 2016; 25:16-27. https://doi.org/10.1158/1055-9965.EPI-15-0578 PMID:26667886

3. Siegel RL, Miller KD, Jemal A. Cancer statistics, 2016. CA Cancer J Clin. 2016; 66:7-30. https://doi.org/10.3322/caac.21332 PMID:26742998

4. Ferlay J, Soerjomataram I, Dikshit R, Eser S, Mathers C, Rebelo M, Parkin DM, Forman D, Bray F. Cancer incidence and mortality worldwide: sources, methods and major patterns in GLOBOCAN 2012. Int J Cancer. 2015; 136:E359-86. https://doi.org/10.1002/ijc.29210 PMID:25220842

5. Chen W, Zheng R, Zhang S, Zeng H, Zuo T, Xia C, Yang Z, He J. Cancer incidence and mortality in China in 2013: an analysis based on urbanization level. Chin J Cancer Res. 2017; 29:1-10. https://doi.org/10.21147/j.issn.1000-9604.2017.01.01 PMID:28373748

6. Ilson DH, Tabernero J, Prokharau A, Arkenau HT, 
Ghidini M, Fujitani K, Van Cutsem E, Thuss-Patience $P$, Beretta GD, Mansoor W, Zhavrid E, Alsina M, George B, et al. Efficacy and Safety of Trifluridine/Tipiracil Treatment in Patients With Metastatic Gastric Cancer Who Had Undergone Gastrectomy: Subgroup Analyses of a Randomized Clinical Trial. JAMA Oncol. 2020; 6:e193531.

https://doi.org/10.1001/jamaoncol.2019.3531

PMID:31600365

7. Kitayama J, Ishigami H, Yamaguchi H, Sakuma Y, Horie $\mathrm{H}$, Hosoya $\mathrm{Y}$, Lefor AK, Sata N. Treatment of patients with peritoneal metastases from gastric cancer. Ann Gastroenterol Surg. 2018; 2:116-23.

https://doi.org/10.1002/ags3.12060

PMID:29863151

8. Zhao J, Liu Y, Zhang W, Zhou Z, Wu J, Cui P, Zhang Y, Huang G. Long non-coding RNA Linc00152 is involved in cell cycle arrest, apoptosis, epithelial to mesenchymal transition, cell migration and invasion in gastric cancer. Cell Cycle. 2015; 14:3112-23.

https://doi.org/10.1080/15384101.2015.1078034

PMID:26237576

9. Song WM, Lin $X$, Liao $X, \mathrm{Hu} D$, Lin J, Sarpel U, Ye Y, Feferman $Y$, Labow DM, Walsh MJ, Zheng X, Zhang B. Multiscale network analysis reveals molecular mechanisms and key regulators of the tumor microenvironment in gastric cancer. Int J Cancer. 2020; 146:1268-80.

https://doi.org/10.1002/ijc.32643 PMID:31463974

10. Fu DG. Epigenetic alterations in gastric cancer (Review). Mol Med Rep. 2015; 12:3223-30.

https://doi.org/10.3892/mmr.2015.3816 PMID:25997695

11. Tian J, Liu G, Zuo C, Liu C, He W, Chen H. Genetic polymorphisms and gastric cancer risk: a comprehensive review synopsis from meta-analysis and genome-wide association studies. Cancer Biol Med. 2019; 16:361-89.

https://doi.org/10.20892/i.issn.2095-3941.2018.0290

PMID:31516756

12. Karimi P, Islami F, Anandasabapathy S, Freedman ND, Kamangar F. Gastric cancer: descriptive epidemiology, risk factors, screening, and prevention. Cancer Epidemiol Biomarkers Prev. 2014; 23:700-13. https://doi.org/10.1158/1055-9965.EPI-13-1057 PMID:24618998

13. Li ZH. A Genome-Wide Association Study of Non-Cardia Gastric Cancer in a Chinese Population Nanjing Medical University. 2012.

14. Abnet CC, Freedman ND, Hu N, Wang Z, Yu K, Shu XO, Yuan JM, Zheng W, Dawsey SM, Dong LM, Lee MP, Ding T, Qiao YL, et al. A shared susceptibility locus in
PLCE1 at 10q23 for gastric adenocarcinoma and esophageal squamous cell carcinoma. Nat Genet. 2010; 42:764-67. https://doi.org/10.1038/ng.649 PMID:20729852

15. Shi $Y, H u Z$, Wu C, Dai J, Li H, Dong J, Wang M, Miao X, Zhou $\mathrm{Y}$, Lu F, Zhang $\mathrm{H}, \mathrm{Hu} \mathrm{L}$, Jiang $\mathrm{Y}$, et al. A genomewide association study identifies new susceptibility loci for non-cardia gastric cancer at 3q13.31 and 5p13.1. Nat Genet. 2011; 43:1215-18.

https://doi.org/10.1038/ng.978 PMID:22037551

16. Lyons K, Le LC, Pham YT, Borron C, Park JY, Tran CT, Tran TV, Tran HT, Vu KT, Do CD, Pelucchi C, La Vecchia C, Zgibor J, et al. Gastric cancer: epidemiology, biology, and prevention: a mini review. Eur J Cancer Prev. 2019; 28:397-412.

https://doi.org/10.1097/CEJ.0000000000000480 PMID:31386635

17. Kamangar F, Sheikhattari P, Mohebtash M. Helicobacter pylori and its effects on human health and disease. Arch Iran Med. 2011; 14:192-99.

PMID:21529109

18. Rota M, Pelucchi C, Bertuccio P, Matsuo K, Zhang ZF, Ito $\mathrm{H}, \mathrm{Hu}$ J, Johnson KC, Palli D, Ferraroni M, Yu GP, Muscat J, Lunet $\mathrm{N}$, et al. Alcohol consumption and gastric cancer risk-A pooled analysis within the StoP project consortium. Int J Cancer. 2017; 141:1950-62. https://doi.org/10.1002/ijc.30891 PMID:28718913

19. Li LF, Chan RL, Lu L, Shen J, Zhang L, Wu WK, Wang L, $\mathrm{Hu} \mathrm{T}$, Li MX, Cho $\mathrm{CH}$. Cigarette smoking and gastrointestinal diseases: the causal relationship and underlying molecular mechanisms (review). Int J Mol Med. 2014; 34:372-80.

https://doi.org/10.3892/ijmm.2014.1786

PMID:24859303

20. de Martel C, Ferlay J, Franceschi S, Vignat J, Bray F, Forman D, Plummer M. Global burden of cancers attributable to infections in 2008: a review and synthetic analysis. Lancet Oncol. 2012; 13:607-15. https://doi.org/10.1016/S1470-2045(12)70137-7 PMID:22575588

21. Yoshida T, Kato J, Inoue I, Yoshimura N, Deguchi H, Mukoubayashi C, Oka M, Watanabe M, Enomoto S, Niwa T, Maekita T, Iguchi M, Tamai H, et al. Cancer development based on chronic active gastritis and resulting gastric atrophy as assessed by serum levels of pepsinogen and Helicobacter pylori antibody titer. Int J Cancer. 2014; 134:1445-57. https://doi.org/10.1002/ijc.28470 PMID:24009139

22. Kara N, Urganci N, Kalyoncu D, Yilmaz B. The association between Helicobacter pylori gastritis and lymphoid aggregates, lymphoid follicles and intestinal metaplasia in gastric mucosa of children. J Paediatr 
Child Health. 2014; 50:605-09.

https://doi.org/10.1111/ipc.12609

PMID:24925694

23. Helicobacter and Cancer Collaborative Group. Gastric cancer and Helicobacter pylori: a combined analysis of 12 case control studies nested within prospective cohorts. Gut. 2001; 49:347-53. https://doi.org/10.1136/gut.49.3.347 PMID:11511555

24. Mapel D, Roberts M, Overhiser A, Mason A. The epidemiology, diagnosis, and cost of dyspepsia and Helicobacter pylori gastritis: a case-control analysis in the Southwestern United States. Helicobacter. 2013; 18:54-65.

https://doi.org/10.1111/j.1523-5378.2012.00988.x PMID:23067108

25. Li M, Sun Y, Yang J, de Martel C, Charvat H, Clifford GM, Vaccarella S, Wang L. Time trends and other sources of variation in Helicobacter pylori infection in mainland China: A systematic review and metaanalysis. Helicobacter. 2020; 25:e12729.

https://doi.org/10.1111/hel.12729 PMID:32686261

26. Lee YC, Chiang TH, Chou CK, Tu YK, Liao WC, Wu MS, Graham DY. Association Between Helicobacter pylori Eradication and Gastric Cancer Incidence: A Systematic Review and Meta-analysis. Gastroenterology. 2016; 150:1113-24.e5.

https://doi.org/10.1053/j.gastro.2016.01.028

PMID:26836587

27. Choi YJ, Kim N. Gastric cancer and family history. Korean J Intern Med. 2016; 31:1042-53.

https://doi.org/10.3904/kjim.2016.147

PMID:27809451

28. Yaghoobi M, Bijarchi R, Narod SA. Family history and the risk of gastric cancer. Br J Cancer. 2010; 102:237-42.

https://doi.org/10.1038/sj.bjc.6605380

PMID: $\underline{19888225}$

29. Oliveira C, Pinheiro H, Figueiredo J, Seruca R, Carneiro F. Familial gastric cancer: genetic susceptibility, pathology, and implications for management. Lancet Oncol. 2015; 16:e60-70.

https://doi.org/10.1016/S1470-2045(14)71016-2 PMID:25638682

30. Hemminki K, Sundquist J, Ji J. Familial risk for gastric carcinoma: an updated study from Sweden. $\mathrm{Br} \mathrm{J}$ Cancer. 2007; 96:1272-77.

https://doi.org/10.1038/sj.bjc.6603722

PMID:17406355

31. Rokkas T, Sechopoulos P, Pistiolas D, Margantinis G, Koukoulis G. Helicobacter pylori infection and gastric histology in first-degree relatives of gastric cancer patients: a meta-analysis. Eur J Gastroenterol Hepatol.
2010; 22:1128-33. https://doi.org/10.1097/MEG.0b013e3283398d37 PMID:20410824

32. Chang YW, Han YS, Lee DK, Kim HJ, Lim HS, Moon JS, Dong SH, Kim BH, Lee JI, Chang R. Role of Helicobacter pylori infection among offspring or siblings of gastric cancer patients. Int J Cancer. 2002; 101:469-74. https://doi.org/10.1002/ijc.10637 PMID:12216076

33. Yan-Hong $H$, Jing L, Hong L, Shan-Shan H, Yan L, Ju L. Association between alcohol consumption and the risk of ovarian cancer: a meta-analysis of prospective observational studies. BMC Public Health. 2015; 15:223.

https://doi.org/10.1186/s12889-015-1355-8 PMID:25885863

34. Kikuchi S. [Risk factors of stomach cancer]. Gan To Kagaku Ryoho. 2001; 28:142-45.

PMID:11242635

35. Baron JH, Sonnenberg A. Hospital admissions for peptic ulcer and indigestion in London and New York in the 19th and early 20th centuries. Gut. 2002; 50:568-70. https://doi.org/10.1136/gut.50.4.568 PMID:11889081

36. Navarro Silvera SA, Mayne ST, Gammon MD, Vaughan TL, Chow WH, Dubin JA, Dubrow R, Stanford JL, West $A B$, Rotterdam H, Blot WJ, Risch HA. Diet and lifestyle factors and risk of subtypes of esophageal and gastric cancers: classification tree analysis. Ann Epidemiol. 2014; 24:50-57.

https://doi.org/10.1016/j.annepidem.2013.10.009 PMID:24239095

37. González CA, Sala N, Rokkas T. Gastric cancer: epidemiologic aspects. Helicobacter. 2013 (Suppl 1); 18:34-38. https://doi.org/10.1111/hel.12082 PMID:24011243

38. Saghier AA, Kabanja JH, Afreen S, Sagar M. Gastric Cancer: Environmental Risk Factors, Treatment and Prevention. J Carcinogene Mutagene. 2013; S14. https://doi.org/10.4172/2157-2518.S14-008

39. Fock KM. Review article: the epidemiology and prevention of gastric cancer. Aliment Pharmacol Ther. 2014; 40:250-60. https://doi.org/10.1111/apt.12814 PMID:24912650

40. Harris CC. Cause and Prevention of Human Cancer. Carcinogenesis. 2015 (Suppl 1); 36:S1. https://doi.org/10.1093/carcin/bgv047 PMID:26106134

41. Park JY, von Karsa L, Herrero R. Prevention strategies for gastric cancer: a global perspective. Clin Endosc. 2014; 47:478-89. https://doi.org/10.5946/ce.2014.47.6.478 
PMID:25505712

42. Correa P. Gastric cancer: overview. Gastroenterol Clin North Am. 2013; 42:211-17.

https://doi.org/10.1016/i.gtc.2013.01.002 PMID:23639637

43. Pomakov P, Guéorgiéva $S$, Stantchéva J, Ténev T, Rizov A. [Gastroduodenal ulcers during the period of acute economical crisis]. J Radiol. 1993; 74:265-67. PMID:8320659

44. Lim SL, Canavarro C, Zaw MH, Zhu F, Loke WC, Chan $\mathrm{YH}$, Yeoh KG. Irregular Meal Timing Is Associated with Helicobacter pylori Infection and Gastritis. ISRN Nutr. 2012; 2013:714970.

https://doi.org/10.5402/2013/714970 PMID:24967249

45. Dikshit RP, Mathur G, Mhatre S, Yeole BB. Epidemiological review of gastric cancer in India. Indian J Med Paediatr Oncol. 2011; 32:3-11. https://doi.org/10.4103/0971-5851.81883 PMID:21731209

46. Yan S, Li B, Bai ZZ, Wu JQ, Xie DW, Ma YC, Ma XX, Zhao $J H$, Guo XJ. Clinical epidemiology of gastric cancer in Hehuang valley of China: a 10-year epidemiological study of gastric cancer. World J Gastroenterol. 2014; 20:10486-94.

https://doi.org/10.3748/wjg.v20.i30.10486 PMID:25132766

47. Garofalo C, Surmacz E. Leptin and cancer. J Cell Physiol. 2006; 207:12-22. https://doi.org/10.1002/jcp.20472 PMID:16110483

48. Huang T, Zhou F, Wang-Johanning F, Nan K, Wei Y. Depression accelerates the development of gastric cancer through reactive oxygen species-activated ABL1 (Review). Oncol Rep. 2016; 36:2435-43. https://doi.org/10.3892/or.2016.5127 PMID:27666407

49. Abnet CC, Freedman ND, Hollenbeck AR, Fraumeni JF Jr, Leitzmann $M$, Schatzkin A. A prospective study of $\mathrm{BMI}$ and risk of oesophageal and gastric adenocarcinoma. Eur J Cancer. 2008; 44:465-71. https://doi.org/10.1016/j.ejca.2007.12.009 PMID:18221867

50. Lin XJ, Wang CP, Liu XD, Yan KK, Li S, Bao HH, Zhao LY, Liu X. Body mass index and risk of gastric cancer: a meta-analysis. Jpn J Clin Oncol. 2014; 44:783-91. https://doi.org/10.1093/jjco/hyu082 PMID:24951830

51. Gao M, Luo J, Chen GX, Fei SJ. Meta-analysis of metformin reducing the gastric cancer risk of patients with type 2 diabetes. Practical Pharmacy And Clinical Remedies. 2017; 20:781-84.

52. Slavin TP, Weitzel JN, Neuhausen SL, Schrader KA, Oliveira C, Karam R. Genetics of gastric cancer: what do we know about the genetic risks? Transl Gastroenterol Hepatol. 2019; 4:55.

https://doi.org/10.21037/tgh.2019.07.02

PMID:31463414

53. Li X, Pasche B, Zhang W, Chen K. Association of MUC16 Mutation With Tumor Mutation Load and Outcomes in Patients With Gastric Cancer. JAMA Oncol. 2018; 4:1691-98.

https://doi.org/10.1001/jamaoncol.2018.2805 PMID:30098163

54. Wang LD, Zhou FY, Li XM, Sun LD, Song $X$, Jin Y, Li JM, Kong GQ, Qi H, Cui J, Zhang LQ, Yang JZ, Li JL, et al. Genome-wide association study of esophageal squamous cell carcinoma in Chinese subjects identifies susceptibility loci at PLCE1 and C20orf54. Nat Genet. 2010; 42:759-63.

https://doi.org/10.1038/ng.648

PMID:20729853

55. Xue W, Zhu M, Wang Y, He J, Zheng L. Association between PLCE1 rs2274223 A > G polymorphism and cancer risk: proof from a meta-analysis. Sci Rep. 2015; 5:7986. https://doi.org/10.1038/srep07986 PMID:25614244

56. Mocellin S, Verdi D, Pooley KA, Nitti D. Genetic variation and gastric cancer risk: a field synopsis and meta-analysis. Gut. 2015; 64:1209-19. https://doi.org/10.1136/gutjnl-2015-309168 PMID:25731870

57. Saeki N, Saito A, Choi IJ, Matsuo K, Ohnami S, Totsuka $\mathrm{H}$, Chiku S, Kuchiba A, Lee YS, Yoon KA, Kook MC, Park $S R$, Kim YW, et al. A functional single nucleotide polymorphism in mucin 1 , at chromosome 1q22, determines susceptibility to diffuse-type gastric cancer. Gastroenterology. 2011; 140:892-902. https://doi.org/10.1053/j.gastro.2010.10.058 PMID:21070779

58. Wu C, Hu Z, He Z, Jia W, Wang F, Zhou Y, Liu Z, Zhan Q, Liu Y, Yu D, Zhai K, Chang J, Qiao Y, et al. Genome-wide association study identifies three new susceptibility loci for esophageal squamous-cell carcinoma in Chinese populations. Nat Genet. 2011; 43:679-84. https://doi.org/10.1038/ng.849 PMID:21642993

59. Liang $P$, Zhang $W$, Wang $W$, Dai $P$, Wang $Q$, Yan W, Wang W, Lei X, Cui D, Yan Z. PLCE1 Polymorphisms and Risk of Esophageal and Gastric Cancer in a Northwestern Chinese Population. Biomed Res Int. 2019; 2019:9765191. https://doi.org/10.1155/2019/9765191 PMID:30931333

60. Reiter RE, Gu Z, Watabe T, Thomas G, Szigeti K, Davis E, Wahl M, Nisitani S, Yamashiro J, Le Beau MM, Loda M, Witte ON. Prostate stem cell antigen: a cell surface 
marker overexpressed in prostate cancer. Proc Natl Acad Sci USA. 1998; 95:1735-40.

https://doi.org/10.1073/pnas.95.4.1735

PMID: $\underline{965086}$

61. Fu YP, Kohaar I, Rothman N, Earl J, Figueroa JD, Ye Y, Malats N, Tang W, Liu L, Garcia-Closas M, Muchmore $B$, Chatterjee N, Tarway $\mathrm{M}$, et al. Common genetic variants in the PSCA gene influence gene expression and bladder cancer risk. Proc Natl Acad Sci USA. 2012; 109:4974-79.

https://doi.org/10.1073/pnas.1202189109

PMID:22416122

62. Yan K, Wu K, Lin C, Jie Z. Impact of PSCA gene polymorphisms in modulating gastric cancer risk in the Chinese population. Biosci Rep. 2019; 39:BSR20181025.

https://doi.org/10.1042/BSR20181025

PMID:31416884

63. Sakamoto H, Yoshimura K, Saeki N, Katai H, Shimoda T, Matsuno Y, Saito D, Sugimura H, Tanioka F, Kato S, Matsukura N, Matsuda N, Nakamura T, et al, and Study Group of Millennium Genome Project for Cancer. Genetic variation in PSCA is associated with susceptibility to diffuse-type gastric cancer. Nat Genet. 2008; 40:730-40.

https://doi.org/10.1038/ng.152 PMID:18488030

64. Yamazaki K, Onouchi $Y$, Takazoe $M$, Kubo $M$, Nakamura $Y$, Hata A. Association analysis of genetic variants in IL23R, ATG16L1 and 5p13.1 loci with Crohn's disease in Japanese patients. J Hum Genet. 2007; 52:575-83.

https://doi.org/10.1007/s10038-007-0156-z PMID:17534574

65. Jiang Y, Li W, Lu J, Zhao X, Li L. Association between PRKAA1 rs13361707 T>C polymorphism and gastric cancer risk: Evidence based on a meta-analysis. Medicine (Baltimore). 2018; 97:e0302. https://doi.org/10.1097/MD.0000000000010302 PMID:29620653

66. Stroup DF, Berlin JA, Morton SC, Olkin I, Williamson GD, Rennie D, Moher D, Becker BJ, Sipe TA, Thacker SB. Meta-analysis of observational studies in epidemiology: a proposal for reporting. Meta-analysis Of Observational Studies in Epidemiology (MOOSE) group. JAMA. 2000; 283:2008-12.

https://doi.org/10.1001/jama.283.15.2008

PMID:10789670

67. Moher D, Liberati A, Tetzlaff J, Altman DG, and PRISMA Group. Preferred reporting items for systematic reviews and meta-analyses: the PRISMA statement. Ann Intern Med. 2009; 151:264-69.

https://doi.org/10.7326/0003-4819-151-4-20090818000135 PMID:19622511
68. Ioannidis JP, Boffetta P, Little J, O'Brien TR, Uitterlinden $A G$, Vineis $P$, Balding DJ, Chokkalingam A, Dolan SM, Flanders WD, Higgins JP, McCarthy MI, McDermott DH, et al. Assessment of cumulative evidence on genetic associations: interim guidelines. Int J Epidemiol. 2008; 37:120-32.

https://doi.org/10.1093/ije/dym159

PMID:17898028

69. Nedovic D, Panic N, Pastorino R, Ricciardi W, Boccia S. Evaluation of the Endorsement of the STrengthening the REporting of Genetic Association Studies (STREGA) Statement on the Reporting Quality of Published Genetic Association Studies. J Epidemiol. 2016; 26:399-404.

https://doi.org/10.2188/jea.JE20150173 PMID:27349199

70. Corso G, Figueiredo J, Biffi R, Trentin C, Bonanni B, Feroce I, Serrano D, Cassano E, Annibale B, Melo S, Seruca R, De Lorenzi F, Ferrara F, et al. E-cadherin germline mutation carriers: clinical management and genetic implications. Cancer Metastasis Rev. 2014; 33:1081-94.

https://doi.org/10.1007/s10555-014-9528-y PMID:25332147

71. Langevin SM, loannidis JP, Vineis P, Taioli E, and Genetic Susceptibility to Environmental Carcinogens group (GSEC). Assessment of cumulative evidence for the association between glutathione S-transferase polymorphisms and lung cancer: application of the Venice interim guidelines. Pharmacogenet Genomics. 2010; 20:586-97. https://doi.org/10.1097/FPC.0b013e32833c3892 PMID:20729793

72. Venice Criteria: Overview. Bioinformatics Review. 2016. http://bioinformaticsreview.com/20151222/ venice-criteria-overview

73. Sagoo GS, Little J, Higgins JP. Systematic reviews of genetic association studies. PLoS Med. 2009; 6:e28. https://doi.org/10.1371/journal.pmed.1000028 PMID:19260758

74. Wacholder S, Chanock S, Garcia-Closas M, El Ghormli L, Rothman N. Assessing the probability that a positive report is false: an approach for molecular epidemiology studies. J Natl Cancer Inst. 2004; 96:434-42. https://doi.org/10.1093/inci/djh075 PMID:15026468

75. Xu CQ, Li LM. Application of false positive report probability in molecular epidemiological study. Chin J Prev Med. 2009; 43:1141-42. 


\section{SUPPLEMENTARY MATERIALS}

Please browse Full Text version to see the data of Supplementary References. 